Review

\title{
Zeolites as Acid/Basic Solid Catalysts: Recent Synthetic Developments
}

\author{
Valentina Verdoliva $^{1}{ }^{,}$Michele Saviano $^{2}(\mathbb{D})$ and Stefania De Luca ${ }^{1, *(D)}$ \\ 1 Institute of Biostructures and Bioimaging, National Research Council, 80134 Naples, Italy; \\ valentina.verdoliva@gmail.com \\ 2 Institute of Crystallography, National Research Council, 70126 Bari, Italy; msaviano@unina.it \\ * Correspondence: stefania.deluca@cnr.it; Tel.: +39-081-253-4514
}

Received: 13 February 2019; Accepted: 1 March 2019; Published: 8 March 2019; Corrected: 6 April 2023

\begin{abstract}
The zeolites are porous solid structures characterized by a particular framework of aluminosilicates, in which the incorporation of the $\mathrm{Al}^{+3}$ ions generates an excess of negative charge compensated by cations (usually alkali or alkali earth) or protons. In the latter case, they are employed as catalysts for a wide variety of reactions, such as dehydration, skeletal isomerization and cracking, while the catalytic activity of basic zeolites has not found, up to now, any industrial or whatever relevant application in chemical processes. In the present review, we firstly intend to give an overview of the fundamental chemical composition, as well as the structural features of the zeolite framework. The purpose of this paper is to analyze their key properties as acid, both Lewis and Brønsted, and basic solid support. Their application as catalysts is discussed by reviewing the already published works in that field, and a final remark of their still unexplored potential as green, mild, and selective catalyst is also reported.
\end{abstract}

Keywords: zeolites; catalysis; solid acid; solid base; chemical modification; alkylation; glycosidation

\section{Introduction}

Zeolites, both naturally occurring or synthetic, are solids of aluminosilicates with crystalline structure and pore size in the microporous range $(<10 \AA)$. They can be described as a framework of $\mathrm{SiO}_{4}$ and $\mathrm{AlO}_{4}$ tetrahedrons cross-linked at their corners by a common oxygen ion. The isomorphic substitution of $\mathrm{Si}^{+4}$ with a trivalent ion $\mathrm{Al}^{+3}$ generates a negative charge in the lattice, which needs to be compensated. Inclusion in the crystal structure of cations, such as alkali or alkali earth metals, compensates the electrovalence of the tetrahedrons containing aluminum. The spaces between the tetrahedrons, which constitute their channels, are naturally occupied by water molecules, so that hydrated zeolites can be generally represented by the formula [1-3]

$$
\mathrm{M}^{+2} \times / \mathrm{n}\left[\left(\mathrm{AlO}_{2}\right)_{\mathrm{x}}\left(\mathrm{SiO}_{2}\right)_{\mathrm{y}}\right] \cdot \mathrm{wH}_{2} \mathrm{O}
$$

Dehydrated zeolites are able to act as molecular sieves, since the dimension of their pores is such as to accept for absorption only molecules of a certain size, shape, and polarity. The available void volume of the zeolites is directly connected to their sieving properties. There are a variety of ways in which they are employed in order to take advantage of these properties. Indeed, alkali cationic zeolites are largely employed as adsorbents for industrial gas purification, such as $\mathrm{CO}_{2}$ capture [4]. They have also a high tendency to capture water and other polar molecules, such as $\mathrm{NH}_{3}$ and $\mathrm{H}_{2} \mathrm{~S}$ [5].

The charge-balancing cations can be partially or totally exchanged by other cations, since they are bonded to the lattice through Coulombic interactions, or either by the ammonium ion, which can be later decomposed, or by heat treatment in gaseous ammonia and a proton, thus generating a Brønsted 
acid form of the zeolite [6]. Recently, protonated zeolites have also been synthesized by employing templating agents, in fact their decomposition leads to having a residual proton, which neutralizes the net negative charge on the framework aluminum atoms (Figure 1). Brønsted acid sites in zeolites are the bridging hydroxyl groups between $\mathrm{Al}$ and Si tetrahedral, while the second source of acidity, Lewis acidity, is ascribed to both framework and extra-framework aluminum species (EFAL) [3].

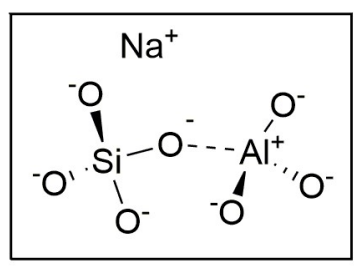

(a)

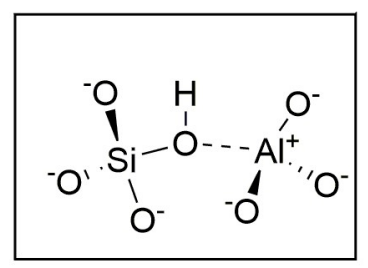

(b)

Figure 1. Representation of the basic (a) and acid (b) sites in Na- zeolites.

In the last thirty years, zeolites, as solid acids, have become extremely successful as catalysts and have been employed for a wide variety of reactions, such as the cracking of carbon-carbon bonds, skeletal isomerizations, polymerization, aromatic alkylation with alkenes or alcohols, and other acid catalyzed reactions [7]. The reason for their success in catalysis is related to several specific features. First of all, zeolites, because of their cage-like porous structure, have a very high surface area and adsorption capacity. In addition, the sizes of their channels and cavities are in the range typical for many molecules of interest (5-12 $⿱$ ) ) and offer at the same time, shape selectivity, which can be used to direct a given catalytic reaction toward the desired product, avoiding undesired side reactions. It is also worth mentioning that for the hydrogenation/dehydrogenation, the activity of the acid zeolites is implemented by metals like $\mathrm{Pt}, \mathrm{Pd}, \mathrm{Ni}$ and, in this case, the solid catalyst acts as a support providing its large surface as a deposit of the metals listed above [4].

The Brønsted acidity of zeolites, when the negative charge present on the Al-substituted framework is compensated by alkaline cations, can be generated by exchanging the synthesis cations with protons. In other words, the number of the Brønsted acid sites of a zeolite depends on the framework $\mathrm{Si} / \mathrm{Al}$ ratio. On the other hand, it has been experimentally demonstrated that, while the density of these acid sites increases with the $\mathrm{Al}^{+3}$ content, a low strength of them is observed, which means the Brønsted acidity of zeolites is also influenced by the presence of the Lewis acidity. More in general, several factors are involved with the catalytic performance of the zeolites, the ability of the substrate to sieve through their pores, the topology of the crystal framework and extra-framework and, also, the electrostatic field generated by the framework Si / $\mathrm{Al}$ ratio $[8,9]$.

Among the solid catalysts employed for the Friedel-Craft aromatic acylation, the zeolites have successfully replaced the Lewis acids $\mathrm{AlCl}_{3}, \mathrm{FeCl}_{3}, \mathrm{SnCl}_{4}$, and $\mathrm{TiCl}_{4}$ for academic and industrial applications, due to the shape selectivity offered by this material. In some cases several metals, in particular, metal triflates such as $\mathrm{La}(\mathrm{OTf})_{3}, \mathrm{Ce}(\mathrm{OTf})_{4}, \mathrm{Y}(\mathrm{OTf})_{3}$, and $\mathrm{Zn}(\mathrm{OTf})_{2}$, were incorporated in their framework and more stable, efficient and recyclable catalysts were obtained. The results in this field allowed advances toward the employment of more eco-compatible methodologies and are greatly reviewed by Sartori and Maggi [10]. The same authors also provided an exhaustive overview about the heterogeneous catalysis applied in the field of the protection and deprotection reactions of functional groups during the organic synthesis. Zeolites are also extensively employed in this field, and have the advantage of providing an easier reaction handling and final purification step, together with an improved selectivity obtained for the protective chemistry [11].

After all, the application of zeolites as acid catalysts has been basically linked with the development of refinery and petrochemistry. In oil refinery, they play a key role, since they result highly active, selective, and durable catalysts, and, as a matter of fact, have replaced mineral acids as the new environmentally friendly solid catalyst. Moreover, it has been proved that these materials 
would have a key role also for the biomass conversion [12,13]. In fact, zeolites, as solid catalysts, offer the advantage of being tunable and recyclable, and are easily separated from reaction mixtures. For all the listed reasons, they are particularly useful for clean and economical production processes of fine chemicals, which is becoming an area of growing interest [14].

In all the cited applications, the zeolites are used for their acid-base properties; however, the chemical discussion for defying this key role is still an active debate [4]. Both acidic and basic zeolites are available, but acidic zeolites have found broad application in important industrial processes as well as in organic chemistry reactions. In comparison, much less attention has been paid, in chemical technology, to the application of the zeolites as "basic catalysts" for academic reactions, while it results totally absent for industrial processes. Indeed, the structure-activity relationship for the microporous basic properties of zeolites is still an open discussion. What is clear is that the zeolite acid-base pair is different from that of the homogeneous acid-base compounds, since their strength is rather influenced by the type of exchangeable cations, aluminum content, structural dimension, and porosity $[4,15,16]$.

Herein, we do not intend to give a comprehensive review, but instead an overview of the most recent organic reactions that have employed zeolites as mild acid or basic solid catalysts for efficient and selective chemical transformation of quite sensitive substrates. In particular, the present paper focuses on the recent results dealing with zeolites as basic/acid solids for organic transformations of peptide and carbohydrate molecules, since wide applications were found on these substrates. Moreover, in recent studies of the modulation activity of zeolites, for both purposes, acid and basic catalysts are reported, in order to prove its valuable application in some of the very useful organic reactions. For all the reported organic process, the employment of zeolites as solid catalysts could avoid the formation of by-products and waste, more usually associated with traditional homogeneous catalysts, besides being easily separated from the final products and also regenerated, if it was necessary, in order to be reused more times in the same process. The final aim is to exploit the potential and the additional advantages of replacing the currently used homogenous catalyst for standard organic reactions with heterogeneous catalysts such as the zeolites.

The structural and composition description of the several types of zeolites, natural or synthetic, is not reported in this review, it has been extensively reviewed in a recently published article [17].

We deal in particular with the Zeolites $\mathrm{A}(\mathrm{Si} / \mathrm{Al}$ ratio usually 1 ) structurally denoted with the code LTA (Linde Type A), in particular with Na-LTA, which contains sodium as cation (Figure 2), it counterbalances the negative charge of the oxygen atoms and has a pore diameter of $4 \AA$ : $\mathrm{Na}_{12}\left[\left(\mathrm{AlO}_{2}\right) \cdot\left(\mathrm{SiO}_{2)}\right]_{12} \cdot 27 \mathrm{H}_{2} \mathrm{O}\right.$.

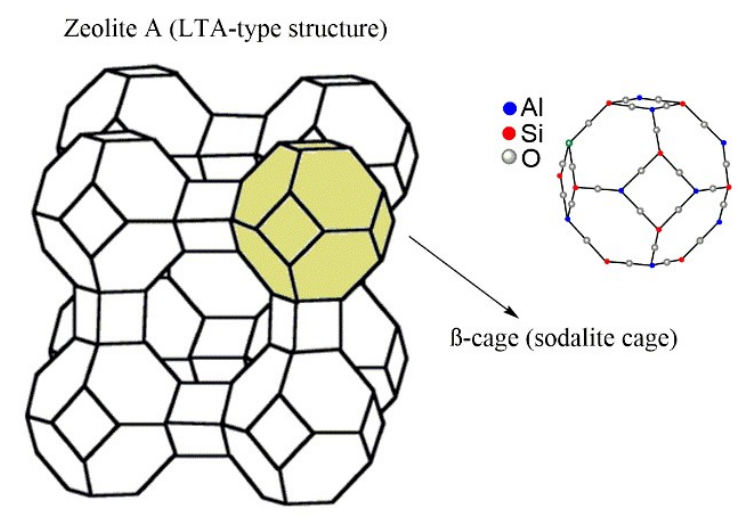

Figure 2. The structure of zeolite Na-LTA.

When $75 \%$ of its sodium is replaced by potassium, it is referred to as a zeolite of $3 \AA$ pore size, alternatively, the replacement of sodium by calcium gives rise to the type of $5 \AA$, with an increased diameter.

Other zeolites taken under consideration in this review (for them catalytic properties) are Zeolite X (FAU-type structure, Si / Al ratio usually 1.2), Zeolite Y (FAU-type structure, Si / Al ratio usually 2.4), 
Zeolite ZSM-5 (MFI-type structure, $\mathrm{Si} / \mathrm{Al}$ ratio usually 15$)$, and Natrolite $\left(\mathrm{Na}_{2}\left[\mathrm{Al}_{2} \mathrm{Si}_{3} \mathrm{O}_{10}\right] \cdot 2 \mathrm{H}_{2} \mathrm{O}\right)[9,18]$ (Figure 3).

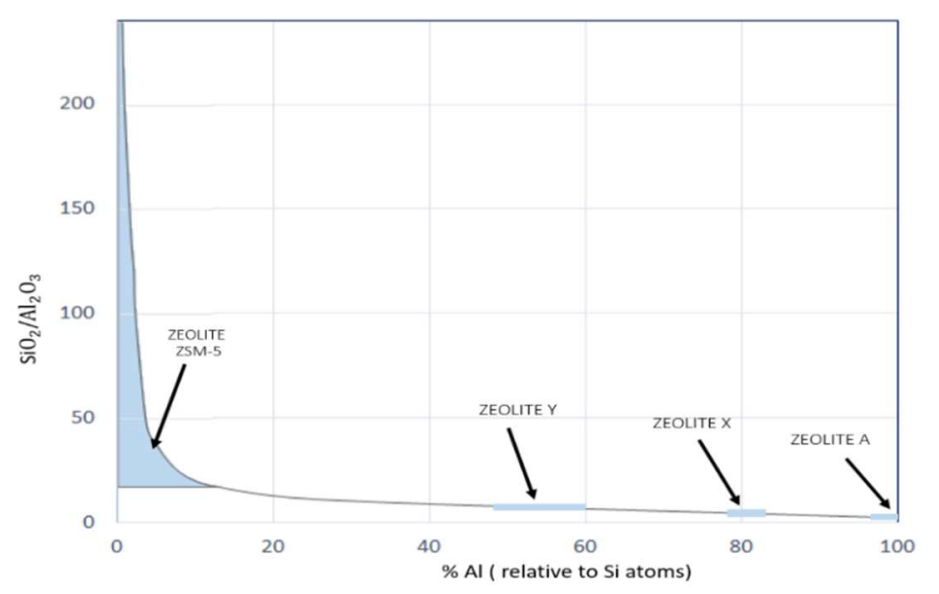

Figure 3. $\mathrm{Al}$ atom concentration and $\mathrm{SiO}_{2} / \mathrm{Al}_{2} \mathrm{O}_{3}$ ratio for various zeolites (adaptation from [9], Nature 1984).

Moreover we also report on several examples of recently published works performed by tuning the acid-base properties of the zeolite catalysts. They depend on the aluminum content in the zeolite framework, as well as on the nonframework charge balancing constituents that can be adequately replaced. Some other references are only cited [19-23].

\section{Glycosidation Reactions Promoted by Molecular Sieves}

\subsection{Glycosidation Reaction via Activation of Glycosyl Trichloro- and N-Phenyltrifluoroacetimidates}

Iadonisi and coauthors performed the glycosidation of primary and secondary saccharides by using acid-washed 4 Å molecular sieves as catalyst that successfully activated glycosyl imidates, acting at the same time as promoters and as drying agents [24]. In major detail, a donor such as trichloro- or trifluoroacetimidate, and an acceptor, employed in a slight stoichiometric excess, were dissolved under an Ar atmosphere in toluene and in presence of activated $\left(\mathrm{T}=200{ }^{\circ} \mathrm{C}\right.$ overnight under vacuum) $4 \AA$ aw (acid washed) MS (Scheme 1). The reaction was heated to a temperature of $70{ }^{\circ} \mathrm{C}$ and then stirred for two hours. Although common acidic activators like lanthanide triflates avoid the high temperature, the obtained yields with molecular sieves as catalyst resulted quite competitive. In order to exclude that residual acids of the acid washed zeolite could have catalyzed the glycosidation reaction, the $4 \AA$ aw MS were washed several times with distillated water before their use and the efficiency of the reaction was not affected.
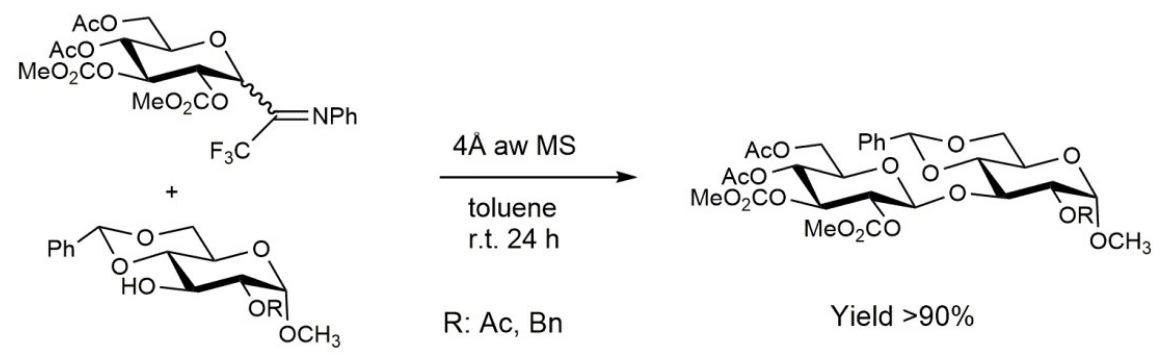

Scheme 1. Activation of glycosyl imidates with activated $4 \AA$ aw MS in a glycosidation reaction.

\subsection{Carbinol Glycosidation Reaction of the 17- $\beta$-Estradiol}

The same authors, by only using the same commercially available $4 \AA$ aw MS, performed a regioselective carbinol glycosidation of $17 \beta$-Estradiol [25]. The reaction proceeded overnight via a mild 
activation of a glycosyl trichloroacetimidate, in 1,2-dichloroethane as solvent; the final glycosidated estradiol was obtained in a satisfactory yield (Scheme 2). The illustrated procedure conferred water solubility to a steroid derivative that has a wide interest for its pharmacokinetic properties.

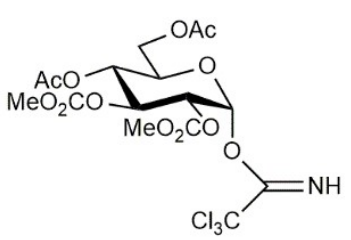

Donor (1 equiv)

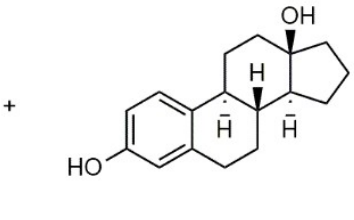

Acceptor (1.1 equiv)

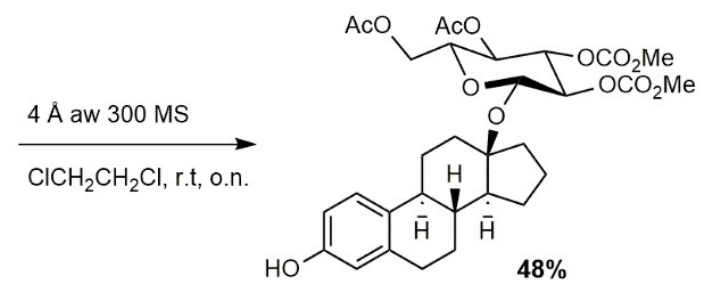

Scheme 2. Regioselective carbinol glycosidation of Estradiol in presence of activated $4 \AA$ aw MS.

\subsection{Selective $\alpha$-Fucosylation for Preparing the Antigenic Trisaccharide Sequence of Lewis X}

Since the $\alpha$-anomer of the L-fucose is widely present in active oligosaccharide sequences, Iadonisi and coauthors have devoted big attention to the development of synthetic strategies to introduce fucose, with its peculiar $\alpha$-linkage, into oligosaccharide domains [26] (Scheme 3).

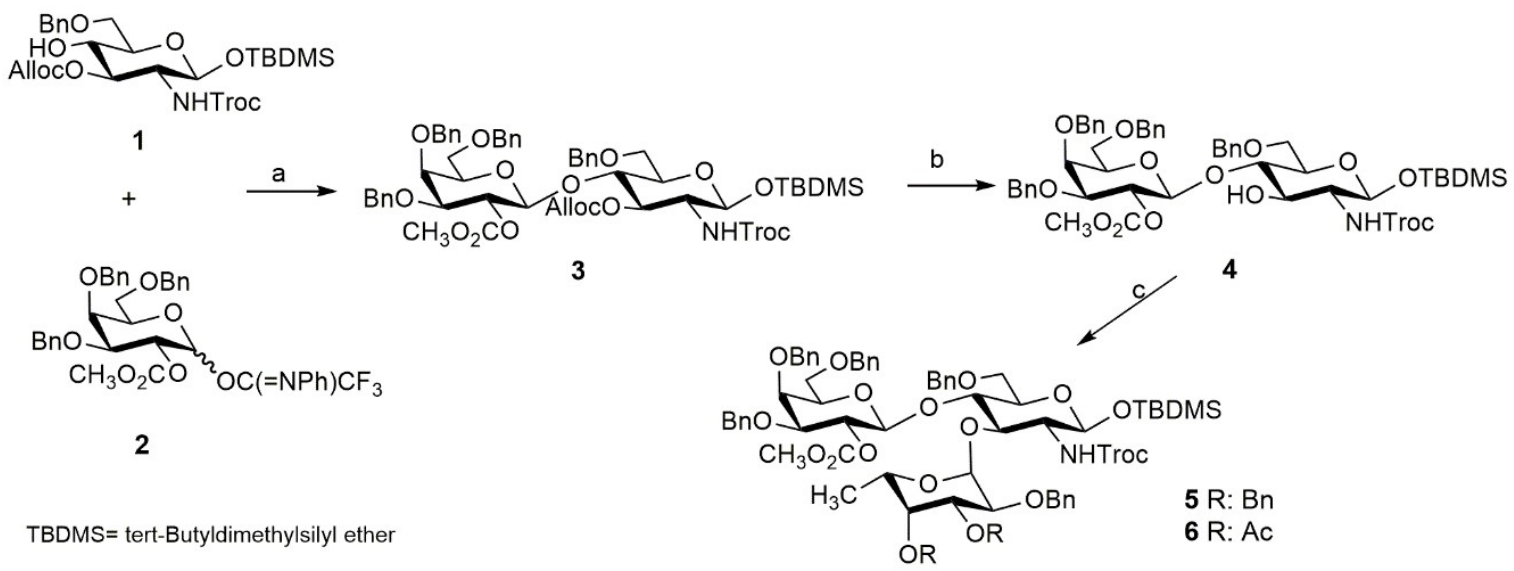

Reaction conditions: a) $4 \AA$ aw MS, dichloroethane, 24 h at $5^{\circ} \mathrm{C}, 24$ h at r.t., $76 \%$; b) $\mathrm{Pd}\left(\mathrm{PPh}_{3}\right)_{4}$, dimedone, THF, $1.5 \mathrm{~h}$ at r.t., $70 \%$; c)

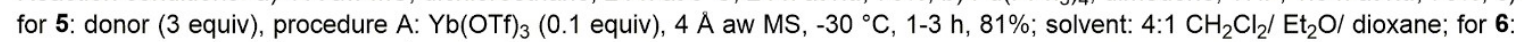
donor (2.5 equiv), procedure B: $4 \AA$ aw MS, from $0{ }^{\circ} \mathrm{C}$ to r.t., $24-36 \mathrm{~h}, 42 \%$; solvent: toluene or $\mathrm{ClCH}_{2} \mathrm{CH}_{2} \mathrm{Cl}$

Scheme 3. $\alpha$-fucosylation reaction promoted by activated $4 \AA$ aw $\mathrm{MS}$ to synthesize a trisaccharide antigenic fragment.

In this regard, the investigation must take into account two important aspects: fucosyl donors are rather reactive and so prone to decomposition and that the $\alpha$-fucosylation reaction is efficiently assisted by the presence of acetyl groups on the donor. A mild synthetic protocol for preparing the antigenic trisaccharide sequence of Lewis $\mathrm{X}$ has proven that $4 \AA$ aw MS are able to promote a highly stereocontrolled $\alpha$-fucosylation, having the advantage of long-range participation of the fucose acetyl protective groups. In major detail, following a procedure previously illustrated, glucosamine $\mathbf{1}$ was reacted with a galactosyl imidate 2 providing that disaccharide 3 was quickly deprotected alcohol 4 for the subsequent $\alpha$-fucosylation reaction. In case of a perbenzylated donor such as the fucosyl $\mathrm{N}$-(phenyl)trifluoroacetoimidate, the reaction took place in a short time $(1-3 \mathrm{~h})$ in the presence of a catalytic amount of $\mathrm{Yb}(\mathrm{OTf})_{3}$. The final yield and the stereoselectivity were totally satisfying for the trisaccharide 5. For a partially acetylated fucose derivative, only activated $4 \AA$ aw $\mathrm{MS}\left(\mathrm{T}=200{ }^{\circ} \mathrm{C}\right.$ overnight under vacuum) were used as catalyst and an excess of two equivalent of the donor (6). The reaction time was prolonged to $24-36 \mathrm{~h}$, the yield was quite satisfying, and complete stereocontrol was achieved. The developed strategy disclosed a remarkable mildness that can characterize the synthetic procedure for preparing important biological saccharidic targets. 


\subsection{Synthesis of a Tetrasaccharide Sequence of Globo $H$}

Globo $\mathrm{H}$ (Figure 4) is an antigen oligosaccharide widely employed for the development of vaccines against some cancers, the terminal portion of it, a tetrasaccharide that was proven to be endowed with biological activity, was nimbly synthesized by Iadonisi and coauthors combining mild reaction strategies [27].

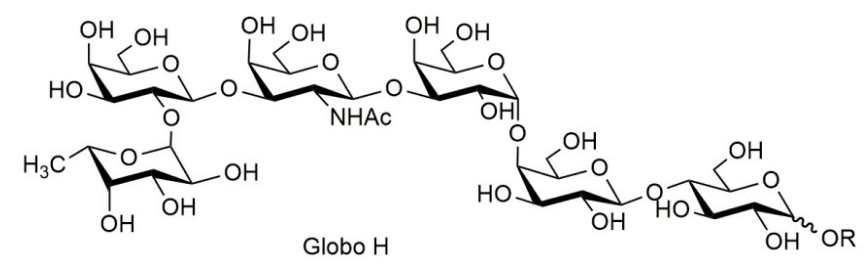

Figure 4. Chemical structure of Globo H.

As shown in Scheme 4, by coupling the azido-functionalized donor 1 with the acceptor 2 in acetonitrile as solvent and $\mathrm{Yb}(\mathrm{OTf})_{3}$ as catalyst, the $\beta$-linked disaccharide 3 was prepared thanks to the $\beta$-directing solvent effect. After deacetylation and successive benzylidene formation, acceptor 4 was coupled with galactose donor 5. For this reaction only, activated $5 \AA$ aw MS were used as catalyst, they gave a higher yield of the final trisaccharide product in a shorter reaction time if compared with the results obtained by using the smaller pore size $4 \AA$ aw MS. Basic deprotection performed with a solution of potassium bicarbonate in methanol allowed the preparation of the acceptor 7 that was subsequently reacted, at low temperature, with fucosyl donor $\mathbf{8}$. The reaction is performed in an $\alpha$-directing system solvent (DCM/diethyl ether/dioxane 4:1:1) and with the efficient activation of $\mathrm{Yb}(\mathrm{OTf})_{3}$. Then, by a reduction procedure, protecting groups such as benzyl and benzylidene were removed, and the azido-group was converted in an amino group. The obtained final product (10) was considered a suitable precursor for developing novel analogs of the original biological target.

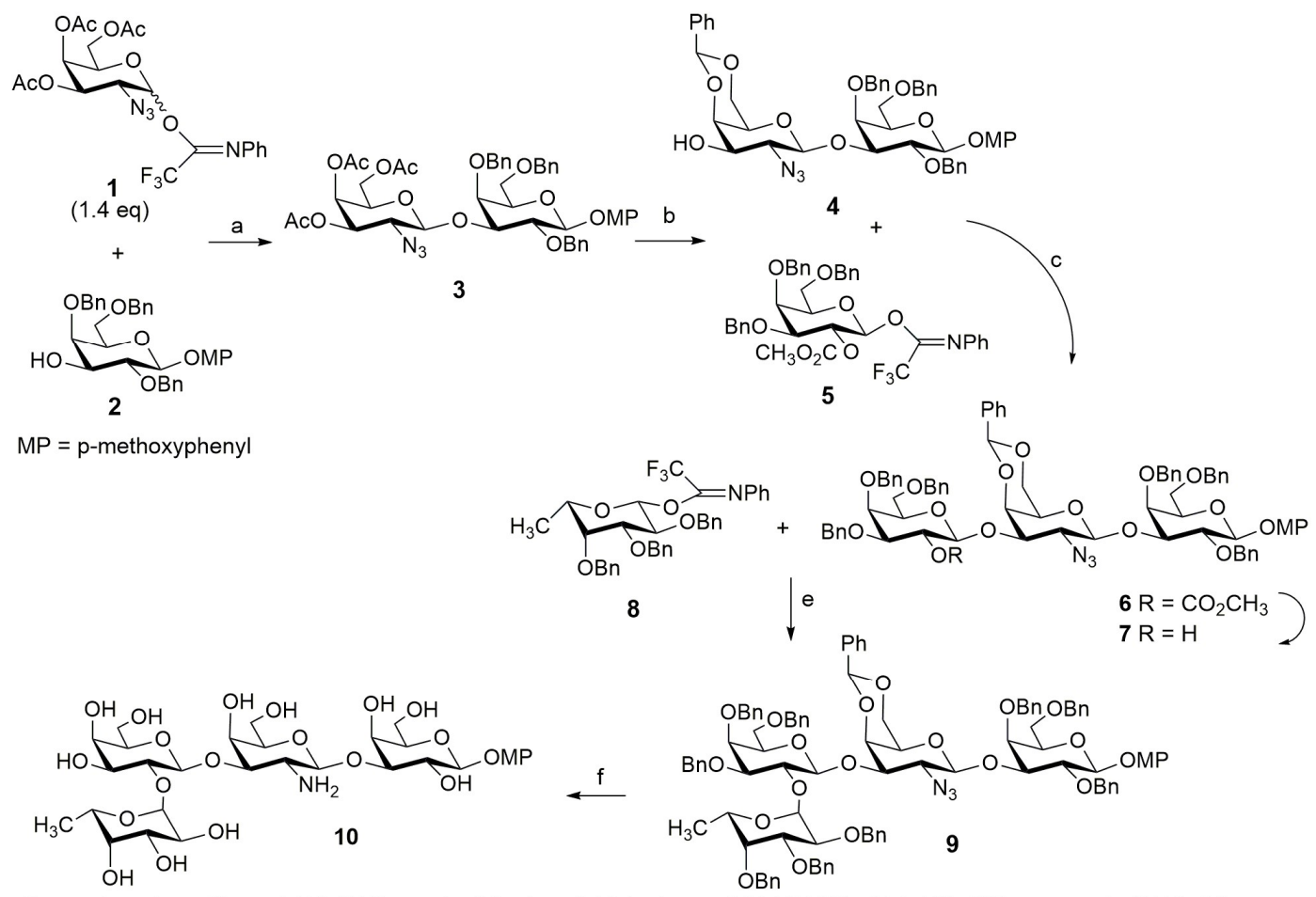

Reagents and conditions: (a) $\mathrm{Yb}(\mathrm{OTf})_{3}$, acetonitrile, from $0{ }^{\circ} \mathrm{C}$ to rt, overnight, $70-77 \%$; (b) $9: 1 \mathrm{MeOH} / \mathrm{aq}$ ammonia (32\%), $3 \mathrm{~h}$, then acetonitrile, benzaldehyde dimethyl acetal, camphorsulfonic acid (cat.) $70{ }^{\circ} \mathrm{C}, 3 \mathrm{~h}, 80 \%$ overall yield; (c) $5 \AA$ aw $\mathrm{MS}$, dichloroethane/cyclohexane $5: 1$, rt, overnight, $75 \%$; (d) $\mathrm{K}_{2} \mathrm{CO}_{3}$, methanol, $40{ }^{\circ} \mathrm{C}, 8 \mathrm{~h}, 89 \%$; (e) $\mathrm{Yb}(\mathrm{OTf})_{3}$, DCM/diethyl ether/dioxane 4:1:1, from $-30{ }^{\circ} \mathrm{Cto} r t, 66 \%$; (f) $\mathrm{Pd}(\mathrm{OH})_{2}, \mathrm{H}_{2}, 3: 3: 1 \mathrm{DCM} / \mathrm{MeOH} / \mathrm{H}_{2} \mathrm{O}, \mathrm{rt}, 90 \%$.

Scheme 4. Synthesis of the tetrasaccharide. 


\section{O-Protection of Sugars Promoted by Molecular Sieves}

\subsection{Protection Procedure of Sugar Alcoholic Functions}

Iadonisi and coauthors achieved interesting results by employing the acid-washed $4 \AA$ molecular sieves (300 aw MS) to install protecting groups on primary and secondary alcoholic functions of saccharides [28]. In particular, benzhydrylation and tritylation were performed under the following conditions. To a mixture of a model saccharide dissolved in anhydrous toluene and in presence of activated 300 aw MS ( $\mathrm{T}=200{ }^{\circ} \mathrm{C}$ overnight under vacuum), several portions of diphenylmethanol were added during a time-lapse of several hours at room temperature. Concerning the tritylation, it was performed by a single addition of a slight stoichiometric excess of triphenyl methanol (Scheme 5). The procedure followed a dehydration mechanism avoiding the employment of strong protic or Lewis acid, it also allowed the protection of the less reactive secondary alcoholic functionalities under mild conditions that result compatible with both, acid and base labile protecting groups. Molecular sieves were thoroughly washed and then reused for another reaction. The protection procedure resulted totally ineffective when performed in presence of standard, not acid washed, $4 \AA$ MS.
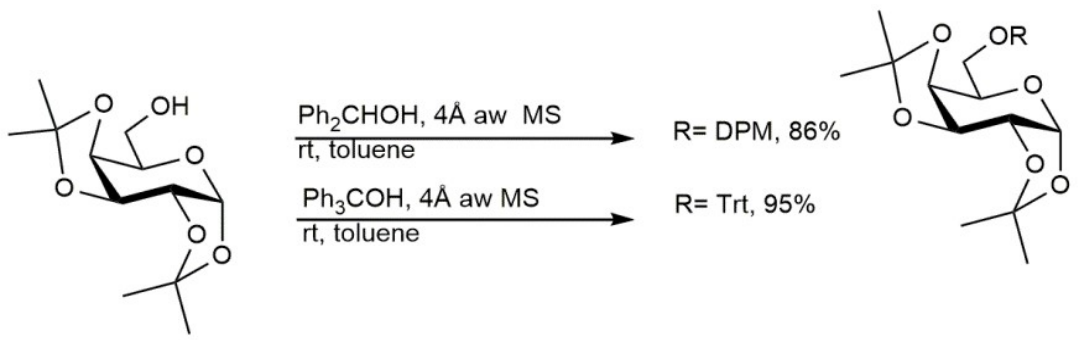

Scheme 5. Benzhydrylation and tritylation of a saccharide in presence of activated $4 \mathrm{~A}$ aw MS.

\subsection{O-Acetylation and De-O-Acetylation of Carbohydrates Activated by Molecular Sieves}

Iadonisi and coauthors have also employed $4 \AA$ MS, without any previous activation, for promoting the selective acetylation of primary and secondary carbohydrate alcoholic groups [29]. The reaction was performed in neat acetic anhydride at $0{ }^{\circ} \mathrm{C}$ and provided the final monoacetylated primary product when continued at room temperature, while the heating of the reaction mixture promoted a di-acetylated carbohydrate synthesis (Scheme 6). In both cases, the final products were obtained in high yields after few hours.

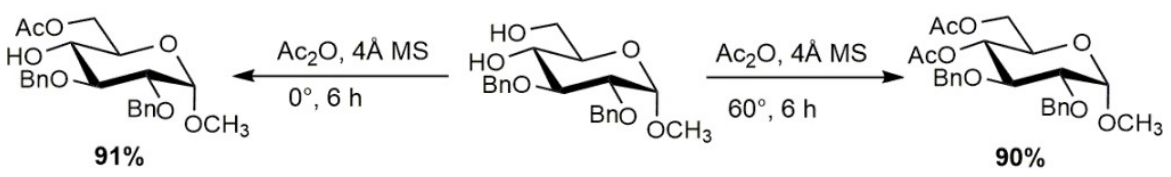

Scheme 6. Acetylation of saccharide promoted by 4 A MS.

Ravindranathan Kartha and coauthors proved that activated $4 \AA$ molecular sieves are able to promote the selective deacetylation of several $O$-acetylated and O-benzylated carbohydrate derivatives [30]. The procedure consist of using methanol as solvent over activated $4 \AA$ molecular sieves, thus the methanolic sodium methoxide was hypothesized to be generated. The reaction allowed the deprotection almost quantitatively after a variable time, from minutes to several hours (Scheme 7). 


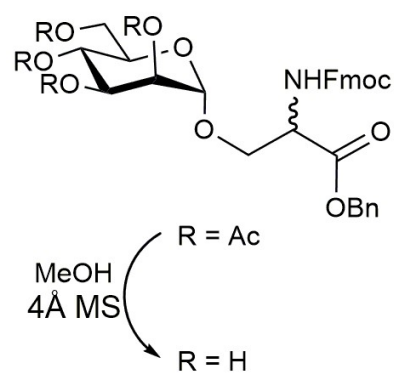

Scheme 7. De-O-acetylation of saccharide promoted by activated 4 Å MS.

\section{Alkylation Reactions Promoted by Molecular Sieves}

\subsection{Side Chain Mono-N-Alkylation of Fmoc-Amino Acids and Peptide Sequences}

Our group reported on an $N$-alkylation as the first reaction promoted by activated $4 \AA$ molecular sieves $\left(280^{\circ} \mathrm{C}, \mathrm{T}=4 \mathrm{~h}\right.$ under vacuum) [31]. The reaction was performed on ortho-Ns-protected basic Fmoc-amino acids (Fmoc-Lys(Ns)-OH; Fmoc-Orn(Ns)-OH; Fmoc-Dab(Ns)-OH; Fmoc-Dap(Ns)-OH) by using different alkyl halides (Scheme 8 ). One of the obtained mono- $N$-alkylated amino acids was introduced as a building block into a peptide sequence.

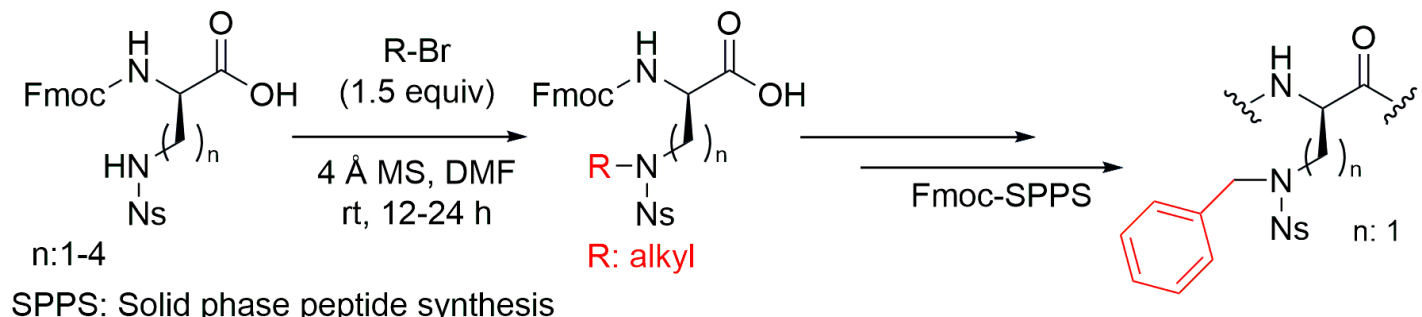

Scheme 8. N-alkylation of nosyl-protected Fmoc-amino acid promoted by activated $4 \AA$ MS.

The success of the obtained results prompted us to explore the new $\mathrm{N}$-alkylation strategy on fully deprotected peptide sequences as postsynthetic modification strategy [32]. The reaction was performed in DMF under an Ar atmosphere and employed under very mild conditions, only activated $4 \AA$ MS as basic catalyst and the appropriate alkyl halide. The nosyl-protected amino group of the amino acid residue performed the nucleophilic substitution, so that a mono- $N$-alkylation was performed on the peptide side chain (Scheme 9). The strategy allowed the introduction of different substituents on model peptides and provided high chemoselectivity and excellent conversion yields.
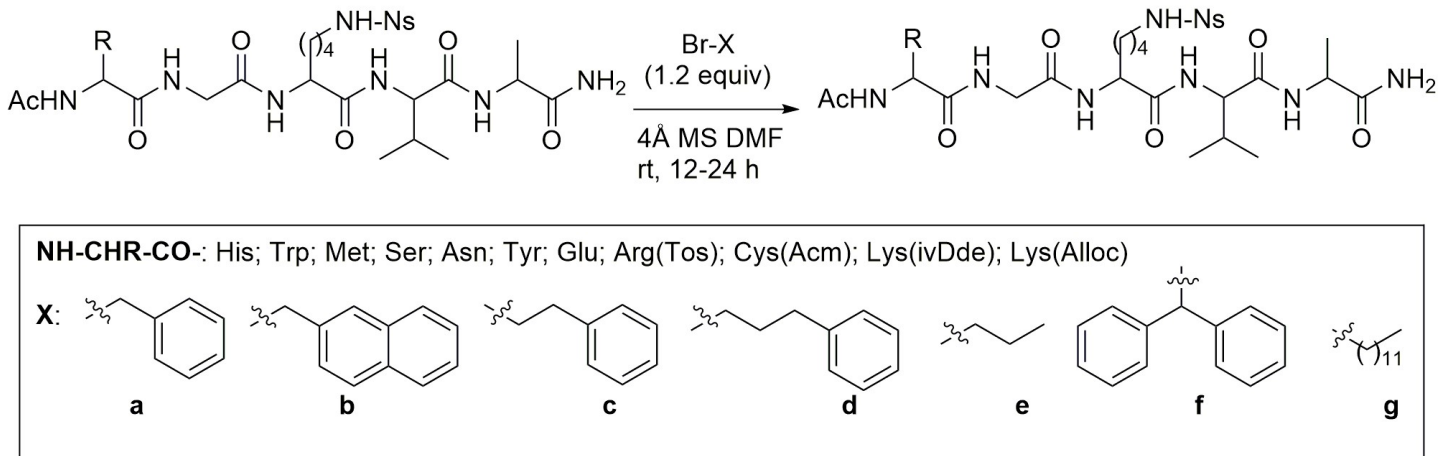

Scheme 9. Chemoselective $N$-alkylation of a peptide sequence promoted by activated $4 \AA$ MS.

\subsection{S-Alkylation Reaction for Introducing Peptide Modification}

Considering the strong nucleophilicity exhibited by the cysteine sulfhydryl group [33], our group explored and tuned the alkylation reaction conditions on peptide sequences containing a cysteine 
residue [34]. In analogy with the $N$-alkylation protocol, postsynthetic $S$-alkylation was promoted by activated $4 \AA$ MS that acts as a base, the mild conditions employed could avoid the racemization of the cysteine residue. The reactivity of the thiol group was explored by performing the reaction on the same model peptide with different alkyl bromides, while the chemoselectivity was assessed by adding at the $\mathrm{N}$-extremity of a peptide model the amino acid residues representative of the range of functional groups usually present on the side chains of natural peptides (Scheme 10). The reaction time was increased from 1 to $3 \mathrm{~h}$, when less reactive alkyl bromides were employed; however, in all cases a high yield of the final product was obtained. The reaction time was drastically reduced when the protocol was further implemented by a microwave irradiation $\left(40{ }^{\circ} \mathrm{C}\right.$ for $\left.5 \mathrm{~min}\right)$ [35]. In addition, the methodology allowed the discrimination of the cysteine thiol group reactivity upon that of other sensitive nucleophilic peptide functionalities. Even in the presence of a lysine residue a polyalkylated product was obtained in a low yield, which was farther reduced when MW-activation was applied.

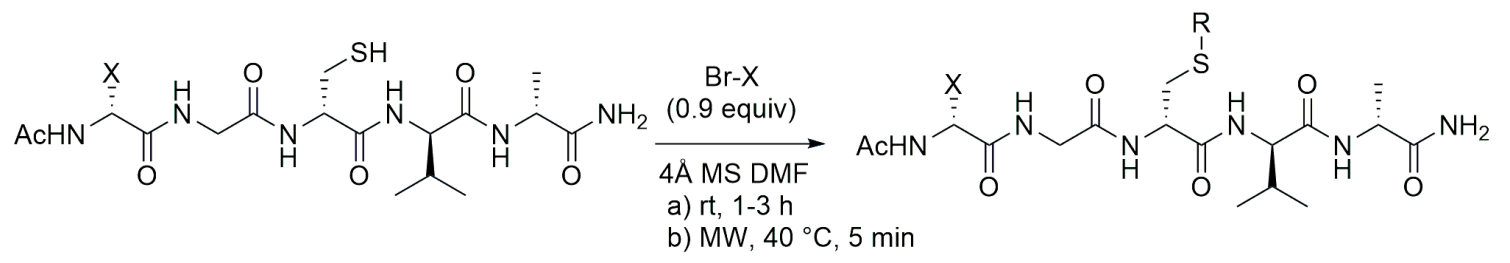

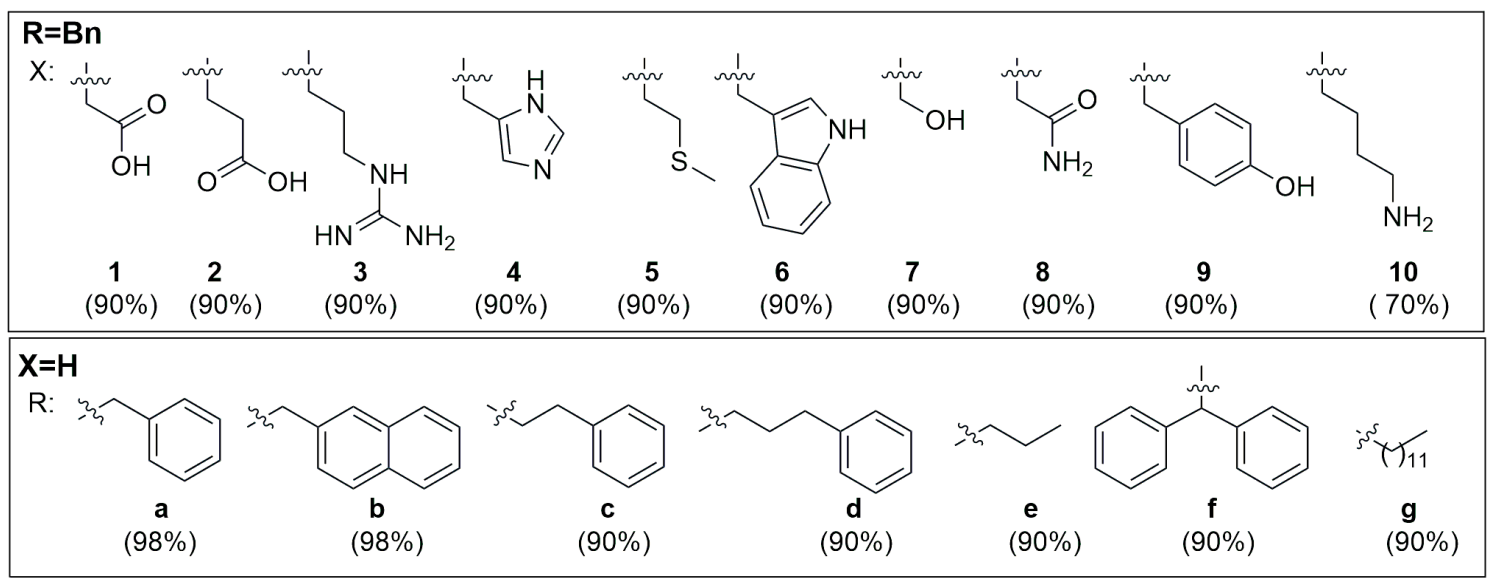

Scheme 10. Chemoselective S-alkylation of a peptide sequence promoted by activated $4 \AA$ MS.

We also succeeded in functionalizing a peptide with polyethylene glycol, a widespread substituent present on bioactive peptides in order to increase their in vivo stability and solubility, as well as with a fluorophore such as 5-(bromo-methyl)fluorescein (Figure 5).

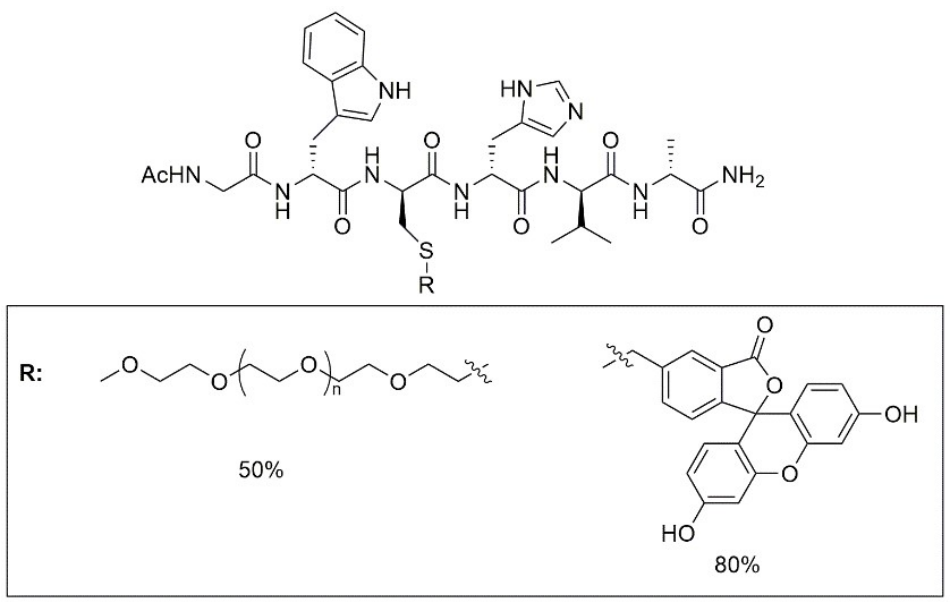

Figure 5. S-alkylation promoted by activated $4 \AA$ MS of peptide with useful substituents. 
The most interesting results were obtained by introducing lipid functionalities in several tailor-made peptides, such as farnesyl and hexadecyl groups (Figure 6), which represent the bioactive portions of their Ras parent proteins [36].

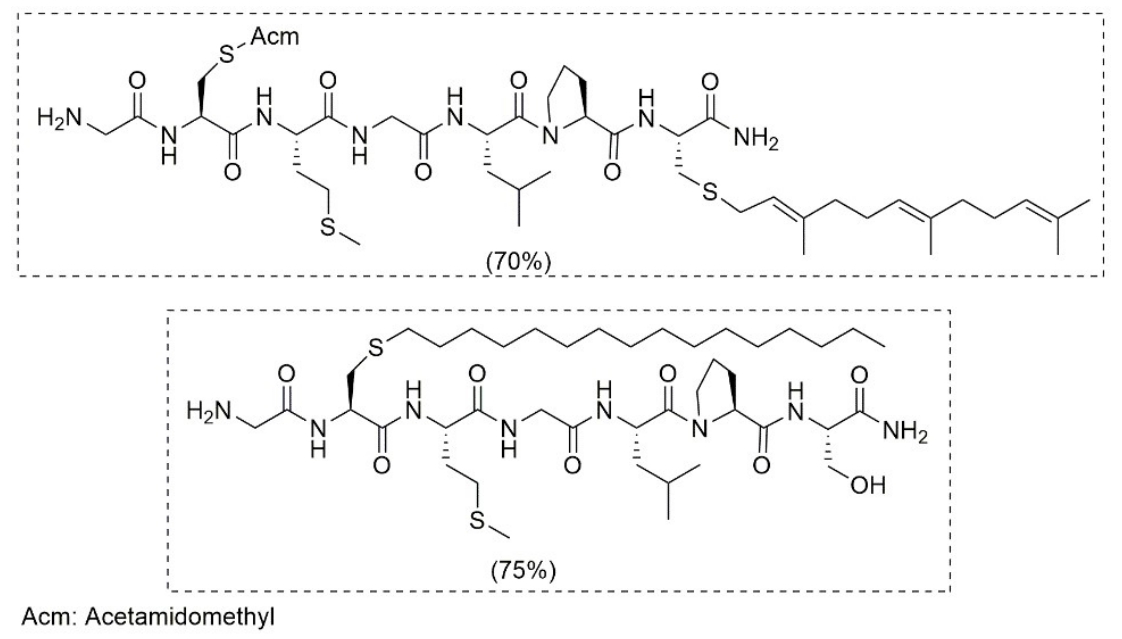

Figure 6. Chemical structure of $S$-lipidated peptides.

\subsection{Solid-Phase S-Alkylation Reaction for Introducing Peptide Modification}

Our group has implemented the developed a postsynthetic $S$-alkylation procedure promoted by $4 \AA$ MS in solid phase, with the aim of considering it a routinely solid-phase peptide synthetic step [37]. The reaction is performed on a peptidyl resin and the chemical process can be considered a solid-state procedure, since both the catalyst (molecular sieves) and the substrate (the peptide anchored on the resin) are provided in solid-state. After a completion of the peptide sequence, the $N$-terminus was acetylated and then the cysteine thiol group was freed from the highly acid labile protecting group (Mmt = 4-methoxytrityl) for the subsequent $S$-alkylation reaction that was performed in DMF under an Ar atmosphere, in presence of activated molecular sieves. The alkyl bromide was employed in a stoichiometric excess and the reaction mixture was kept under stirring for $15 \mathrm{~h}$ at room temperature. The efficiency of the solid phase $S$-alkylation was investigated by reacting a peptide model with different alkyl bromides (Scheme 11).

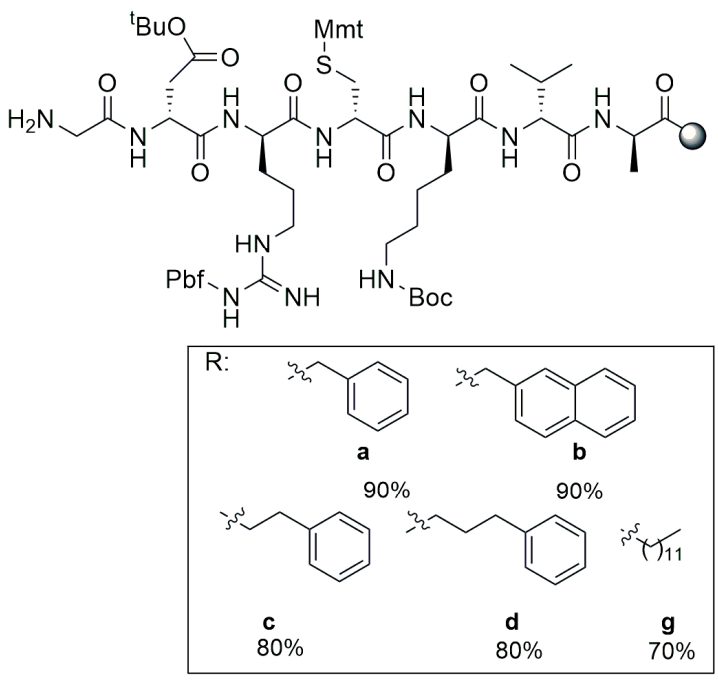

(i) TFA/TIS/DCM (1:5:94)

$10 \times 3$ min washings

(ii) $\mathrm{R}-\mathrm{Br}$ (5 equiv), $4 \AA \mathrm{MS}$

DMF, rt, $15 \mathrm{~h}$

(iii) TFA/ $\mathrm{H}_{2} \mathrm{O} / \mathrm{TIS}(97: 2: 1), 3 \mathrm{~h}$<smiles>[X]SC[C@H](NC(=O)[C@H](CCCNC(=N)N)NC(=O)[C@H](CC(=O)O)NC(=O)CN)C(=O)N[C@@H](CCCCN)C(=O)N[C@H](C(=O)N[C@@H](C)C(N)=O)C(C)C</smiles>

Mmt: 4-Methoxytrityl; TIS:Triisopropylsilane

Scheme 11. Solid-phase $S$-alkylation of peptide sequences anchored on resin promoted by activated $4 \AA$ A MS. 
By combining both protocols—the $4 \AA$ MS solution and solid-phase strategy-it was possible to prepare a multialkylated peptide, such as the C-terminal N-RAS decapeptide shown in Scheme 12. It contains the palmityl group introduced in solid phase and the farnesyl that was necessarily introduced on the fully deprotected functionalized peptide 2 . In fact, the farnesyl could avoid the final acid treatment for the deprotection and the cleavage of the peptide, which can affect its stereochemistry.

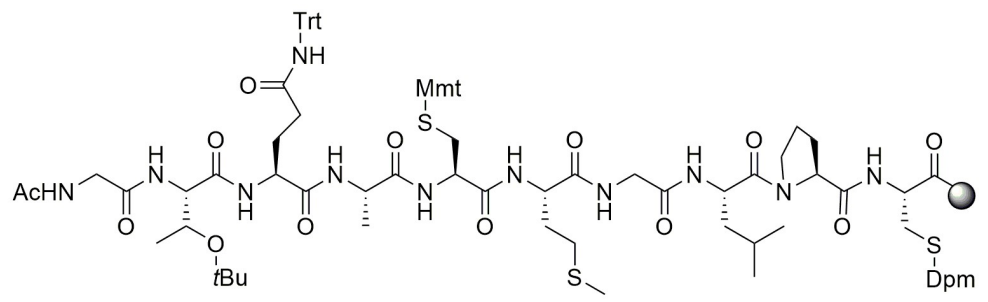

1

(i) TFA/TIS/DCM (1:5:94), $10 \times 3$ min washings (ii) Hexadecyl-Br ( 5 equiv), $4 \AA$ MS, DMF, rt, $15 \mathrm{~h}$ (iii) peptide synthesis

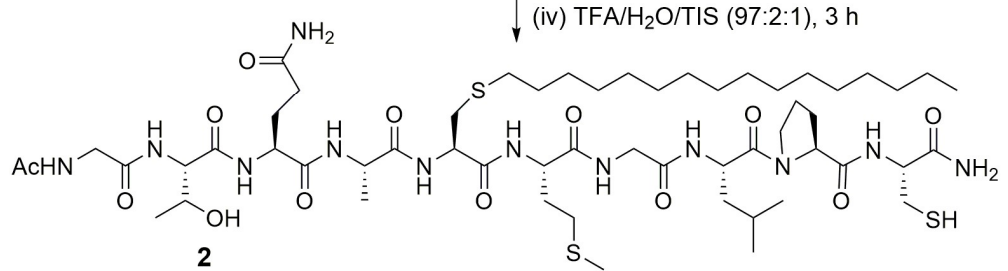

2 (v) Fernesyl-Br (1.2 equiv), $4 \AA$ MS, DMF, rt, $3 \mathrm{~h}$

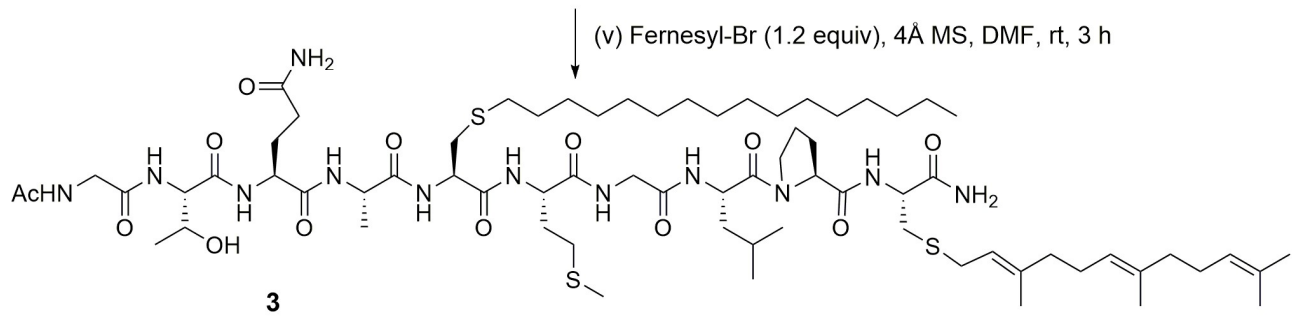

Scheme 12. Solution and solid-phase approach promoted by activated $4 \AA$ MS to perform a multialkylation.

\subsection{Chemoselective Glycosylation of Peptides through S-Alkylation Reaction}

The $S$-alkylation procedure promoted by activated $4 \AA$ molecular sieves was also employed by our group to prepare $S$-linked glycopeptides [38]. The reaction was performed on peptide sequences containing the sensitive cysteine residue that could react with the chosen glycosyl halide, in DMF, under an Ar atmosphere, and in the presence of activated molecular sieves as the basic catalyst. A good chemoselectivity for this site-directed functionalization of the cysteine thiol group was obtained, even in presence of other nucleophiles. In addition, the reactivity of the sulfhydryl was explored toward a certain number of monosaccharides (acetobromo- $\alpha$-D-glucose; acetobromo- $\alpha$-D-galactose; 1-chloro- $N$-acetyl-glucosamine) and also toward a disaccharide such as the acetobromo-maltose. The reaction occurred through a $\mathrm{S}_{\mathrm{N}} 2$ mechanism and allowed the formation of $S$ - $\beta$-linked glycopeptide (Scheme 13). The final compounds were prepared in moderate yields; however, they were obtained without any manipulation of the sugar derivative that was in all cases commercially available, neither a peculiar activation of the thiol group was necessary in order to achieve chemo and stereoselective cysteine functionalization. 


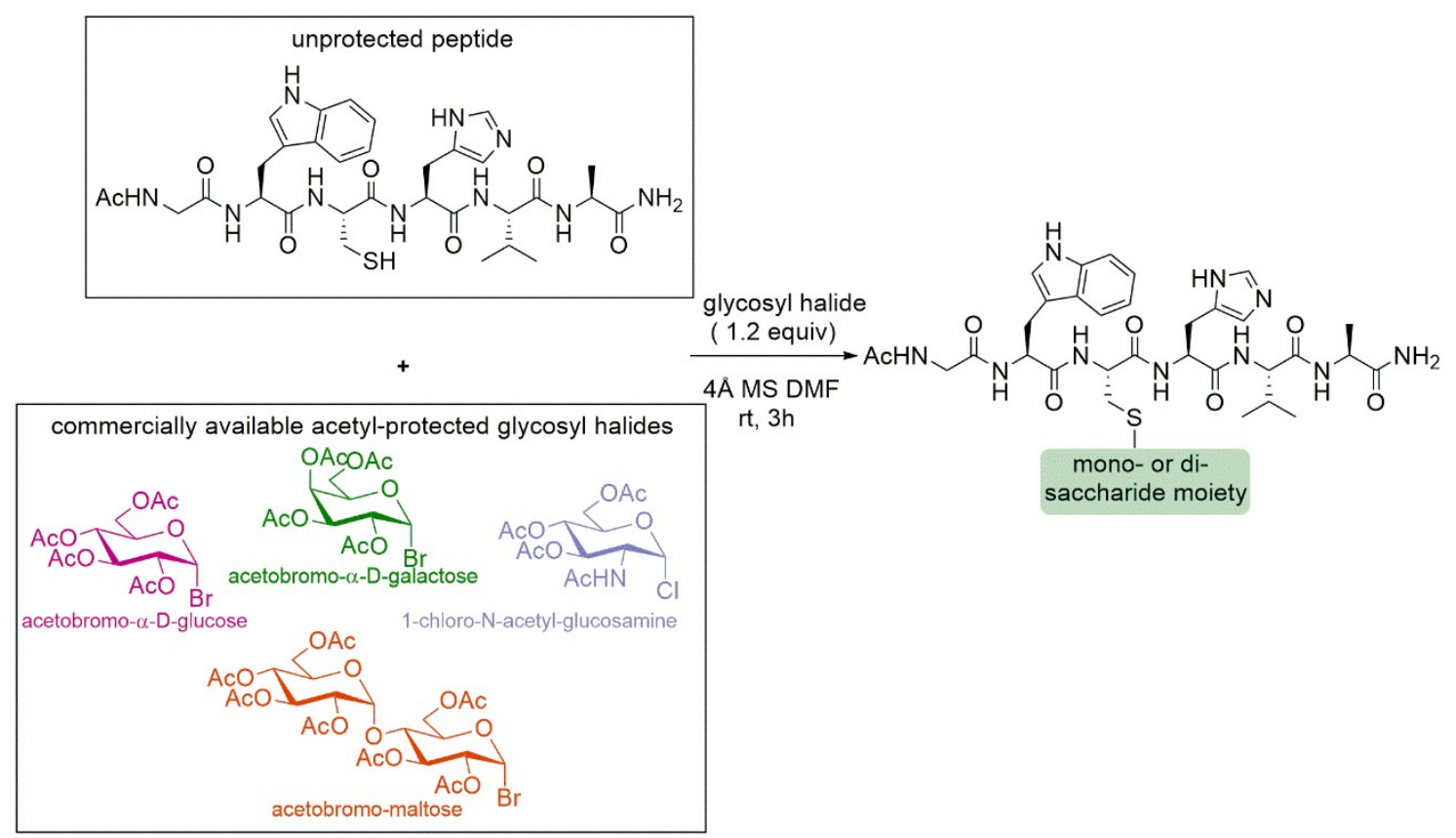

Scheme 13. S-glycosylation of peptide sequences promoted by activated $4 \AA$ MS using different carbohydrate derivatives.

\subsection{Lanthionine-Containing Peptide Obtained via Cysteine S-Alkylation on Cyclic Sulfamidates}

Our group has also developed a $4 \AA$ MS promoted strategy to prepare lantipeptides, peptide molecules that contain the unusual amino acid lanthionine [39]. The reaction consists of the $S$-alkylation of a cysteine, already inserted in a peptide sequence, on a cyclic sulfamidate. The obtained modified peptide contains a stereochemically pure lanthionine residue (Scheme 14). The mild reaction conditions allowed for the employment of orthogonal and peptide-compatible protecting groups on the sulfamidate derivatives, which is a key objective of the proposed procedure, since they can be selectively removed in order to perform the subsequent cyclization and introduce the thioether ring, typical structural motif of the natural lantibiotics. The successful outcome of the new methodology, both in terms of efficiency and chemoselectivity, was proved by the excellent yield values (80-95\%) found for the obtained monoalkylated peptides.
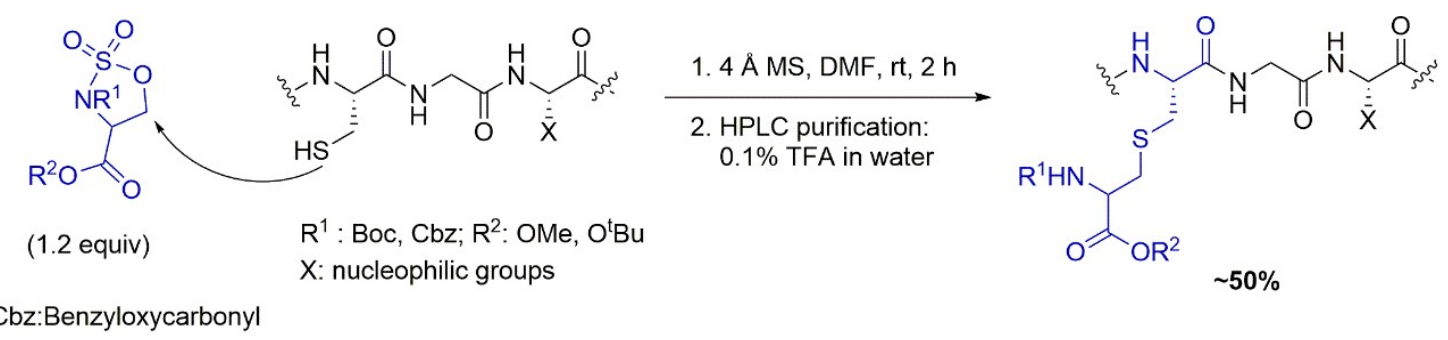

Scheme 14. S-alkylation of peptide sequences performed on cyclic sulfamidates and promoted by activated $4 \AA$ MS.

As an application of the new methodology, the synthesis of Hal $\beta$ ring B was successful carried out, it serves as a template for future preparation of lantibiotic analogs (Scheme 15). 


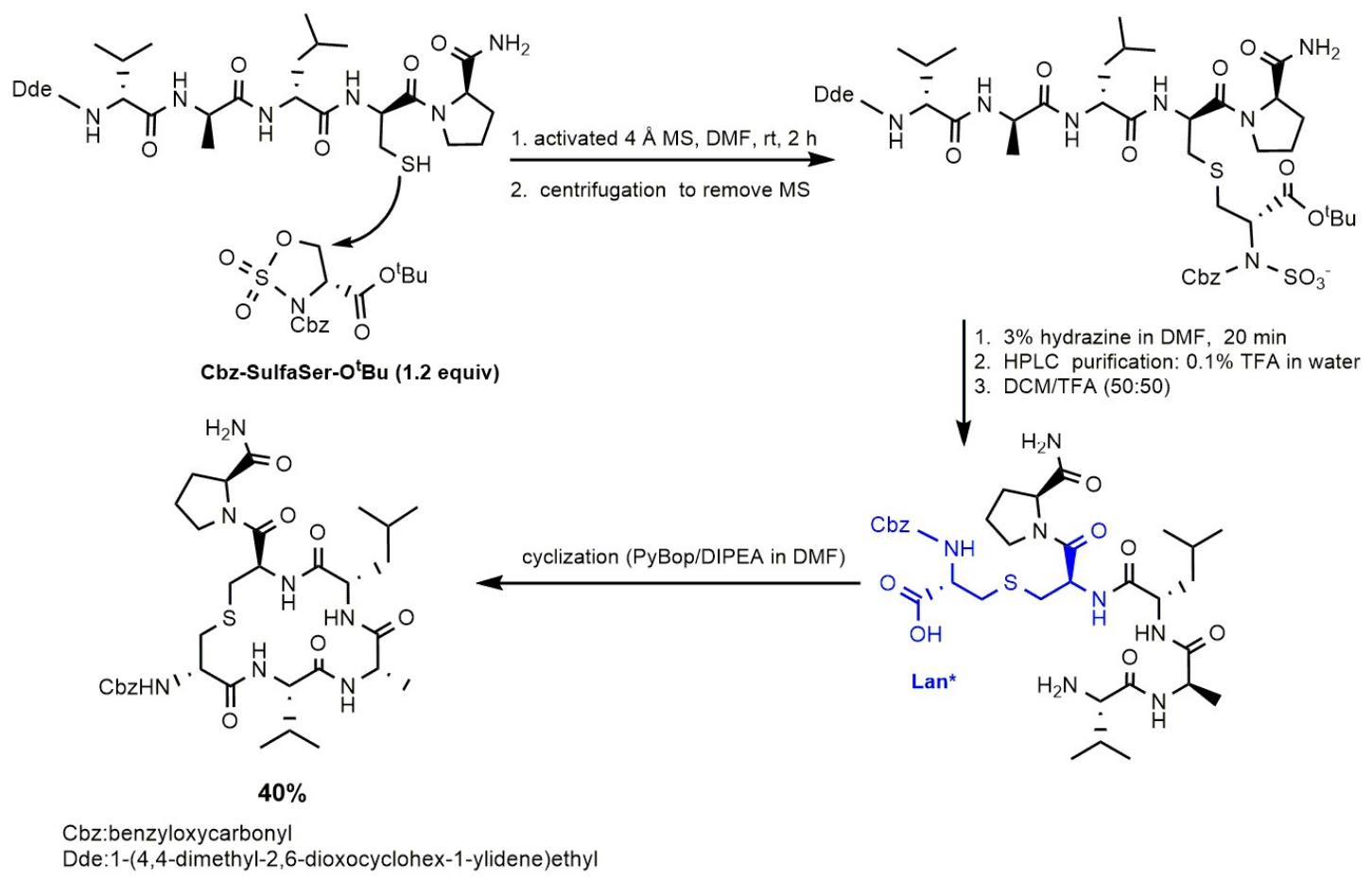

Scheme 15. S-alkylation of peptide sequence promoted by activated $4 \AA$ MS to prepare bioactive lantibiotic fragment.

\subsection{Benzylation of Arylcyanamides Performed via Acid Catalysis of Zeolites}

Azarifar and coauthors performed a substitution reaction of cyanamides by employing benzyl bromide and several arylcyanamides in acetonitrile, at $65^{\circ} \mathrm{C}$ and in presence of acid zeolite as catalyst. It is worth remembering that substituted cyanamides are useful and widespread employed building blocks for the preparation of biologically active substrates, such as antiviral and anticancer agents. Several zeolites have been employed, some naturally occurring in the Lewis acid form (Na-Y and Na-ZSM-5) and others obtained by preparing their Brønsted H-form (H-Y and H-ZSM-5). The exchange of $\mathrm{Na}^{+}$with the proton was performed by treatment of the zeolite with $\mathrm{NH}_{4} \mathrm{NO}_{3}$ followed by a drying and calcination process (Scheme 16) [40].

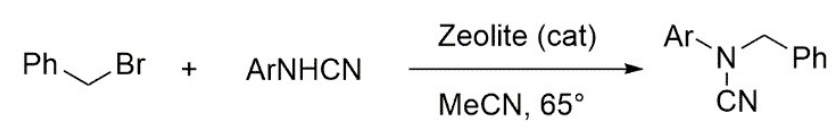

Scheme 16. $N$-benzylation of arylcyanamide promoted by acidic zeolites.

The zeolite H-Y exhibited the best result in terms of yield, probably due to the high number of acidic sites and the dimension of the zeolite pores together with the presence of the super-cages inside the aluminosilicate solid.

The hypothesized reaction path is reported in Scheme 17 and suggests a $\mathrm{S}_{\mathrm{N}} 2$ mechanism into the zeolite channels by acidic catalysis assistance.

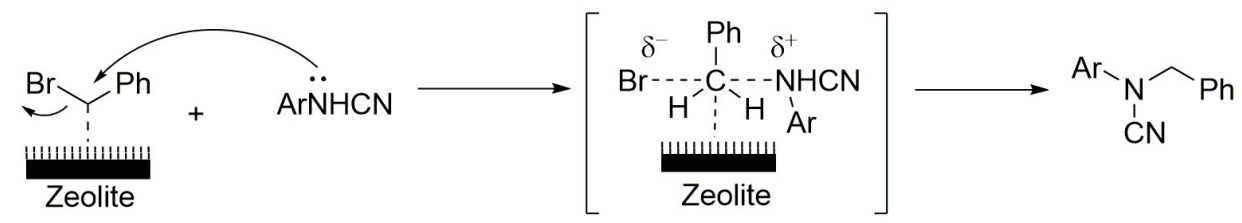

Scheme 17. Hypothesized mechanism for N-benzylation of arylcyanamides promoted by acidic zeolite. 
It is important to refer that the catalyst was recovered by filtration and reused, keeping the original activity. Moreover, the reaction was totally unsuccessful in absence of the zeolite.

\subsection{Microwave Irradiation Promotes the N-Alkylation of Imidazole in Presence of a Basic Zeolite as Catalyst}

The alkylation of heterocycles is an important synthetic step for the preparation of biological active compounds such as fungicides and anticonvulsants. Costarrosa and coauthors reported on an alkylation reaction performed on imidazole by using different alkylating agents, alkaline-exchanged $X$-type zeolite as catalyst, and microwave irradiation to promote the chemical process [41].

The sodium ions of $13 \mathrm{X}$ zeolites were exchanged with some other alkaline earth ions by employing $2 \mathrm{M}$ solutions of the corresponding salts, $\mathrm{CaCl}_{2}, \mathrm{BaCl}_{2}$, and $\mathrm{Sr}\left(\mathrm{NO}_{3}\right)_{2}$. The procedure was performed as follows (Scheme 18). The imidazole and the chosen zeolite, previously dried at $353 \mathrm{~K}$, were blended in a Teflon vessel, then an excess of 9 equivalent of alkylating agent (1-Br-butane, 2-Br-butane, and 1 -Br-hexane) was added. The reactor vessel was placed in a microwave oven and irradiated at 300 and $700 \mathrm{~W}$ during different time-lapses $(1,3$, and $5 \mathrm{~min})$. The reaction products were extracted in acetone.
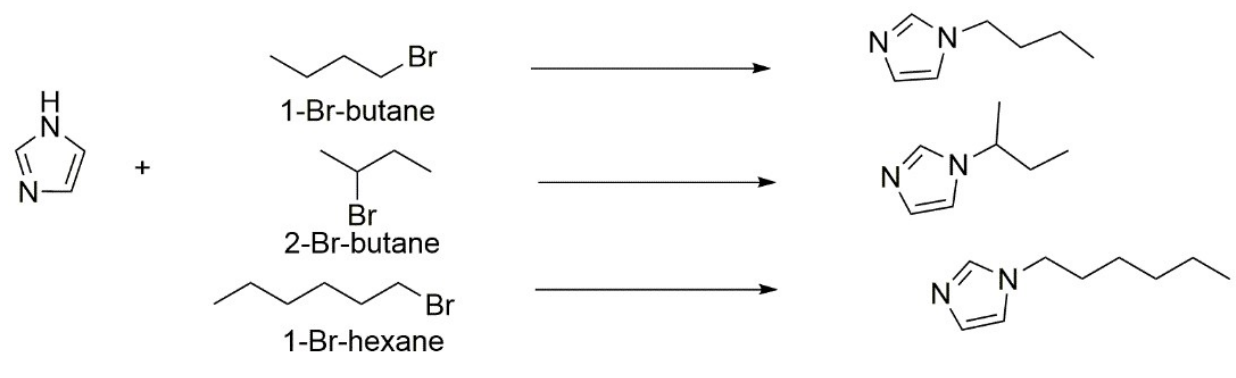

Scheme 18. N-Alkylation of imidazole with different alkylating agents in presence of basic zeolites.

The obtained results indicated the following trend of basicity $\mathrm{NaX}>\mathrm{CaX}>\mathrm{BaX}>\mathrm{SrX}$, which is not related to the basic character of the alkaline earth ions exchanged zeolites $(\mathrm{BaX}>\mathrm{SrX}>\mathrm{CaX})$. In general, the comprehensive analysis of the performed experiments assessed that the catalytic activity depends on the basicity of the employed zeolite, the polarizing ability of the exchanged cation, and the power of the employed microwave irradiation. For 1-Br-butane and 2-Br-butane, the best catalyst was revealed to be $\mathrm{NaX}$ when microwave irradiation was produced at $300 \mathrm{~W}$. An increase in this value would affect the activity only of the less basic catalysts. In the case of 1-Br-hexane, the found trend was different. In fact, at the highest power of $700 \mathrm{~W}$, the best catalyst resulted to be SrX with the shortest time of irradiation, which is in agreement with the strongest basic character of $\mathrm{SrX}$ zeolite.

\section{Useful Examples of Broad Scope Reactions Promoted by Molecular Sieves}

\subsection{Synthesis of $\alpha$-Aminophosphonates by Using Natural Natrolite as Reusable and Efficient Catalyst}

Bahari and coauthors reported on a novel high yielding procedure for synthesizing $\alpha$-aminophosphonates [42]. The one-pot reaction uses aromatic aldehydes or ketones, substituted anilines, and trialkyl phosphites under solvent-free conditions and Natrolite zeolite as catalyst. The optimized reaction conditions were found by employing 4-methylbenzaldehyde ( $1 \mathrm{mmol})$, aniline (1 mmol), and triethyl phosphine $(1 \mathrm{mmol})$; concerning the catalyst, the optimum amount of natural Iranian natrolite was found to be $0.05 \mathrm{~g}$ (Scheme 19). It is important to underline that the reaction does not occur in absence of the catalyst and that it could be easily recovered by filtration after addition of ethylacetate to the mixture. As final step, the catalyst was washed of water and ethanol and dried in order to be reused without any loss of efficiency.

In conclusion, the developed procedure revealed to be efficient (high yield in a short reaction time), environmentally friendly (little waste was produced), and economically convenient (a natural and reusable zeolite was employed as catalyst). 


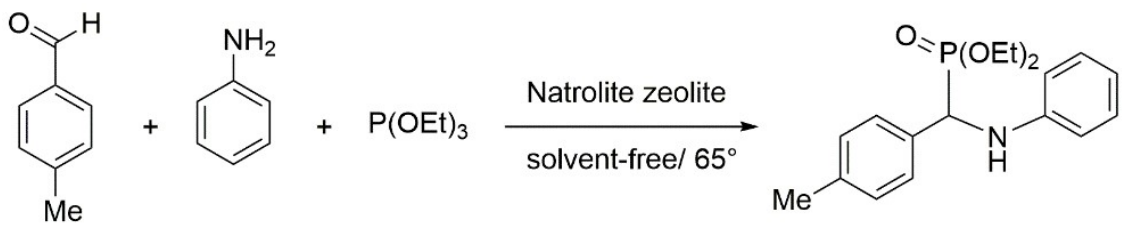

Scheme 19. $\alpha$-aminophosphonate catalyzed by Natrolite zeolite.

\subsection{Metal-Catalyzed Enolization of Nucleophiles Precursors}

Hasegawa and coauthors developed an efficient catalytic activation protocol for generating metal enolate, by employing nitromethane as nucleophile and Lewis acid, such as chiral Ni(II) ions, in combination with $4 \AA$ MS [43]. The reaction is performed in alcohol as solvent and provides the active enolate that can be subsequently involved in a Michael addition reaction with $\alpha, \beta$-unsaturated carbonyl electrophiles. Following the hypothesized mechanism, the catalytic activity of the molecular sieves, employed without any preactivation, consist of capturing a proton (Scheme 20). In other words, the molecular sieves behaved an effective base, even with a smaller pore size of $3 \AA$, while the $5 \AA$ MS resulted much less efficient

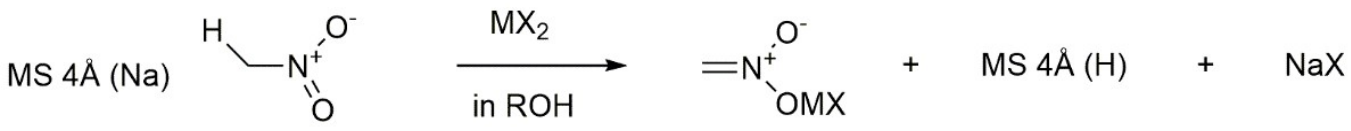

Scheme 20. Ni(II) nitronate generated by the catalyst activity of basic $4 \AA$ MS that captures the $\alpha$-proton of a nucleophile precursor.

\subsection{Different Base-Catalyzed Reactions Promoted by Methylammonium- Faujasite}

It is well-known that the basicity of the zeolites increases with the decrease of the electronegativity of the compensating cations, since it enhances the electron density on the framework oxygens. Therefore, the basic strength of the cationic zeolites follows the order $\mathrm{Li}^{+}<\mathrm{Na}^{+}<\mathrm{K}^{+}<\mathrm{Rb}^{+}<\mathrm{Cs}^{+}$. With this idea in mind, Martins and coauthors prepared exchanged Cs-FAU and also exchanged methylammonium-FAU, which showed the highest ion exchange degree.

(CH3)NH3+-FAU catalytic power for several reactions, such as Knoevenagel and Claisen-Shmidt condensation as well as alcoholysis of propylene oxide (Scheme 21), gave the best results, and is six times more active than Cs-FAU [44].

a.

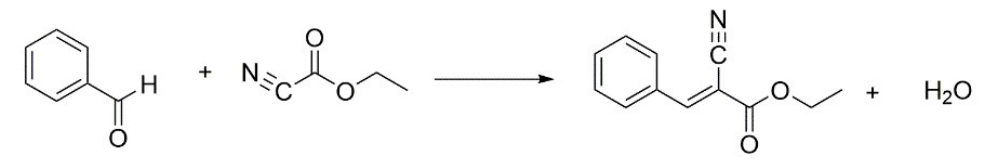

b.

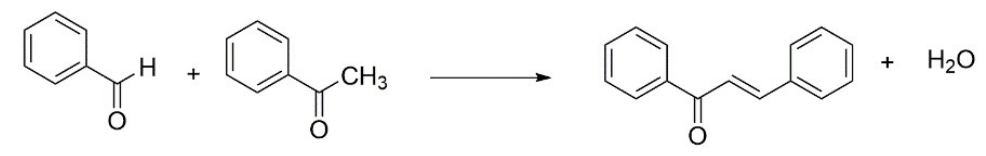

c.<smiles>COCC(O)CO</smiles>

a. Knoevenagel condensation of benzaldehyde with ethyl cyanoacetate; $\mathbf{b}$. Claisen-Schmidt condensation of benzaldehyde with acetophenone; c. Propylene oxide alcoholysis with methanol.

Scheme 21. Three different base-catalyzed reactions promoted by methylammonium FAU zeolites.

The experimental studies were performed on both modified FAU types, $\mathrm{X}(\mathrm{Si} / \mathrm{Al}=1.4)$ and $\mathrm{Y}$ $(\mathrm{Si} / \mathrm{Al}=2.5)$. The TPD- $\mathrm{CO}_{2}$ test (temperature-programmed desorption of $\left.\mathrm{CO} 2\right)$ found that the zeolites 
containing the highest content of aluminum present also have a higher basicity character. On the other hand the O1s-XPS measurements (X-ray photoelectron spectroscopy) proved that the presence of the organic cation methyl-ammonium increases the basic character of the zeolite, since it exhibited the highest ion exchange degree, so that the highest number of catalytic sites. It was proved that the acid-base pair of the alkyl-ammonium-FAU is more efficient in providing basic catalysis for all the performed reactions, which confirm the great potential of the new low-cost developed catalyst.

\subsection{Benzene Ethylation Performed with Ethanol in Presence of Modified Acidic Zeolite}

Ethylbenzene is one of the most used chemical intermediate for several synthetic processes; in fact, it is the main feedstock for the production of styrene, while it is also utilized for the manufacture of cellulose acetate, acetophenone, diethylbenzene, propylene oxide, and other substances.

Emana and Chand reported on the ethylation of benzene by an electrophilic substitution performed upon catalysis of an acidic zeolite that activates the alkene obtained by dehydration of ethanol [45]. In details, all reagents were placed in a continuous down flow tubular quartz reactor allocated in a controlled furnace. Two different kinds of zeolite, previously activated for $1 \mathrm{~h}$ in nitrogen atmosphere, were employed. One of them was the Brønsted acidic H-ZSM- 5 zeolite, obtained from the Na-ZSM- 5 upon exchange of the cations with protons by using a $1 \mathrm{M}$ solution of $\mathrm{NH}_{4} \mathrm{NO}_{3}$. Subsequently, the impregnation of H-ZSM- 5 with magnesium and boron was performed by using a solution of boric acid and magnesium nitrate as source of the desired elements. The best results, in terms of both selective and high-yield production, of ethylbenzene were obtained by employing $\mathrm{Mg}$ (5\%)-B (4\%)-HZSM-5 zeolite; in fact, other by-products were obtained in a negligible yield (Scheme 22).

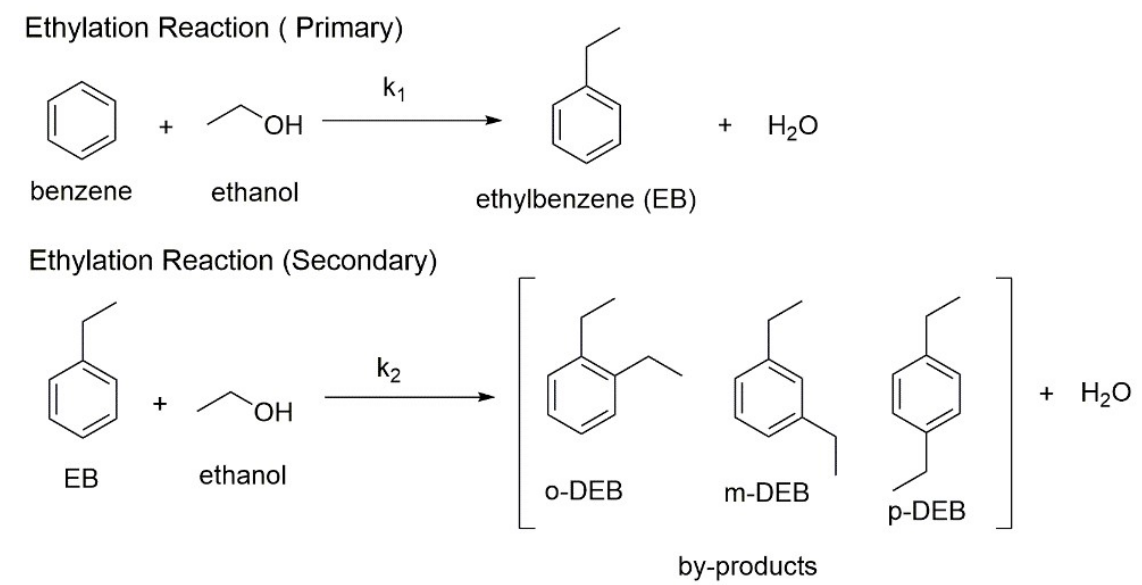

Scheme 22. Reactions occurring during the ethylation of benzene with ethanol in presence of modified acidic zeolite.

5.5. Basic Mesoporous Zeolite Proved to Be an Efficent Catalyst for Several Reactions: Condensation, Hydroxylation, and Cycloaddition Reactions

Mesoporous ZSM-5 zeolite was prepared under basic conditions and its calcined form was treated with $\mathrm{NH}_{4} \mathrm{OH}$. Sarmah and coauthors studied the catalytic activity of the obtained basic zeolite by performing several base catalyzed reactions such as the synthesis of substituted styrenes, carbinolamides, naphthopyrans, and cyclic carbonates via Knovenagal condensation, amide hydroxylation, one-pot multicomponent reaction, and cycloaddition reactions (Scheme 23) [46]. 


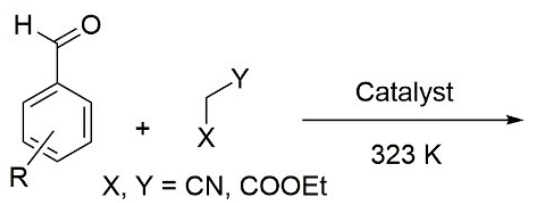<smiles>[X]C([X])=Cc1ccccc1</smiles>

a. Influence of substrate in the Knoevenagel condensation reaction using Basic-Meso-ZSM-5 catalyst<smiles>[R]c1ccc(C(=O)NCO)cc1</smiles>

b. Influence of substrate $\mathrm{HCHO}$ amount and water content in the hydroxylation of benzamide<smiles></smiles>

$\mathrm{R}=\mathrm{H}, 4-\mathrm{NO}_{2}, 4-\mathrm{OMe}, 4-\mathrm{Me}, 4-\mathrm{Cl}$<smiles>[R]c1ccc(C2C(C#N)=C(N)Oc3c2ccc2ccccc32)cc1</smiles>

c. Catalytic activity data obtained in the one-pot multi-component synthesis of naphthpyrans

Scheme 23. Basic mesoporous zeolite catalyzes the synthesis of substituted styrenes, carbinolamides, naphthopyrans, and cyclic carbonates.

\subsection{Synthesis of Polysubstituted Cyclopropanes Catalyzed by Basic Zeolite}

Rama and coauthors reported on a very convenient protocol to promote the one-pot two-step synthesis of substituted cyclopropane. The reaction utilizes substituted benzyl halides, aromatic aldehydes, pyridine, acetonitrile derivatives, and potassium-exchanged $\mathrm{Y}$ zeolites as basic catalyst (Scheme 24). The same reaction performed in absence of the zeolite gave no product, since the pyridine basicity was insufficient for catalyzing the final addition that provides the cyclopropane, while it could only promote the Knoevenagel condensation [47].

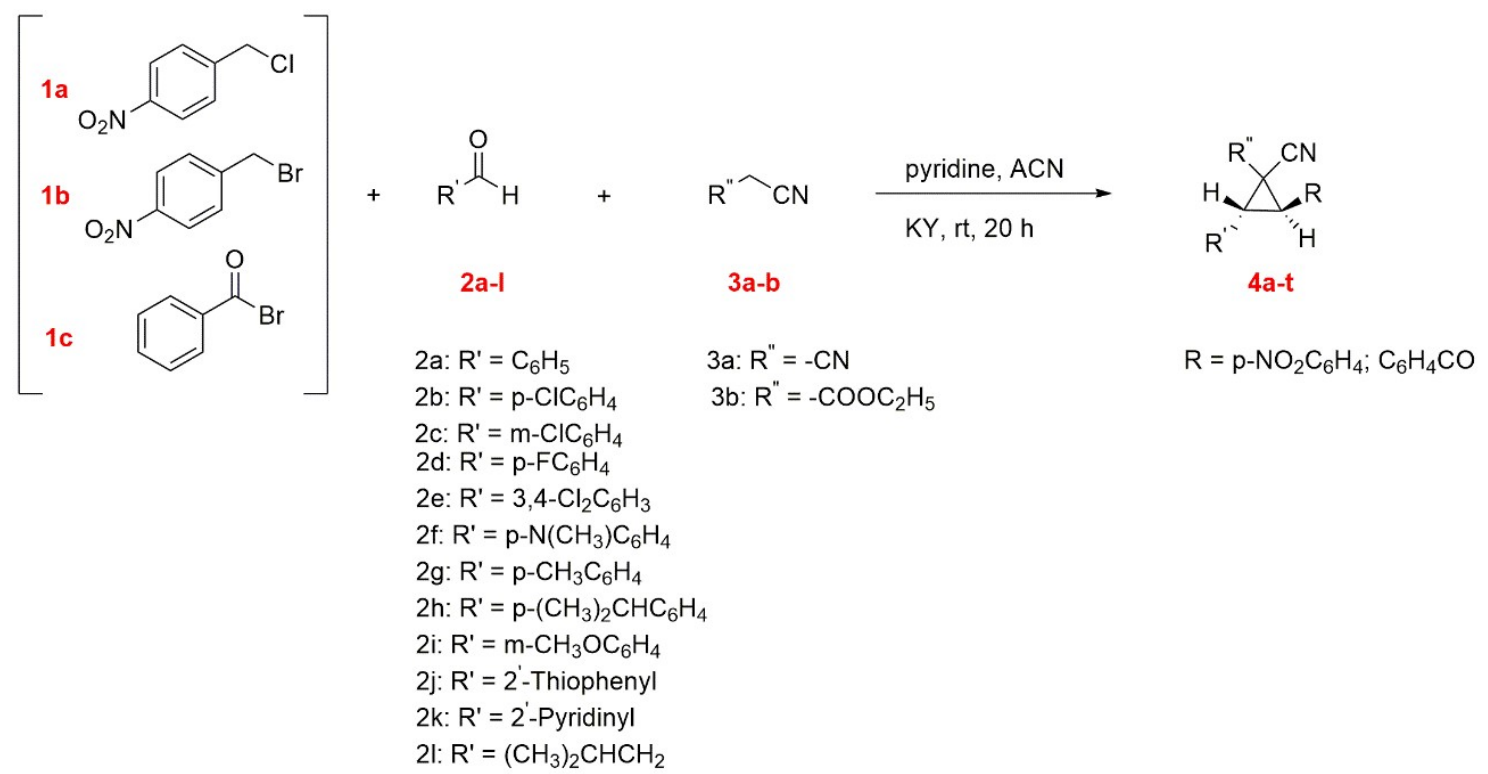

Scheme 24. Synthesis of polysubstituted cyclopropanes promoted by basic KY zeolites.

The catalyst was prepared by a cation substitution procedure performed on $\mathrm{NaY}$ with nitrate solution of potassium, lithium and cesium. The yield of the catalyzed reactions followed the basicity degree of the zeolites ( $\mathrm{Cs} Y>\mathrm{KY}>\mathrm{NaY}>\mathrm{LiY}$ ). Indeed, $\mathrm{KY}$ was preferred to $\mathrm{Cs} Y$ for cost effectiveness 
and easy handling reasons. The exchanged cation increased the negative charges on the aluminum center, which was transferred to the adjacent oxygen atom. It is believed that the basic cites are localized on the surface-bound metal oxides and the plausible catalytic mechanism is reported in Scheme 25.

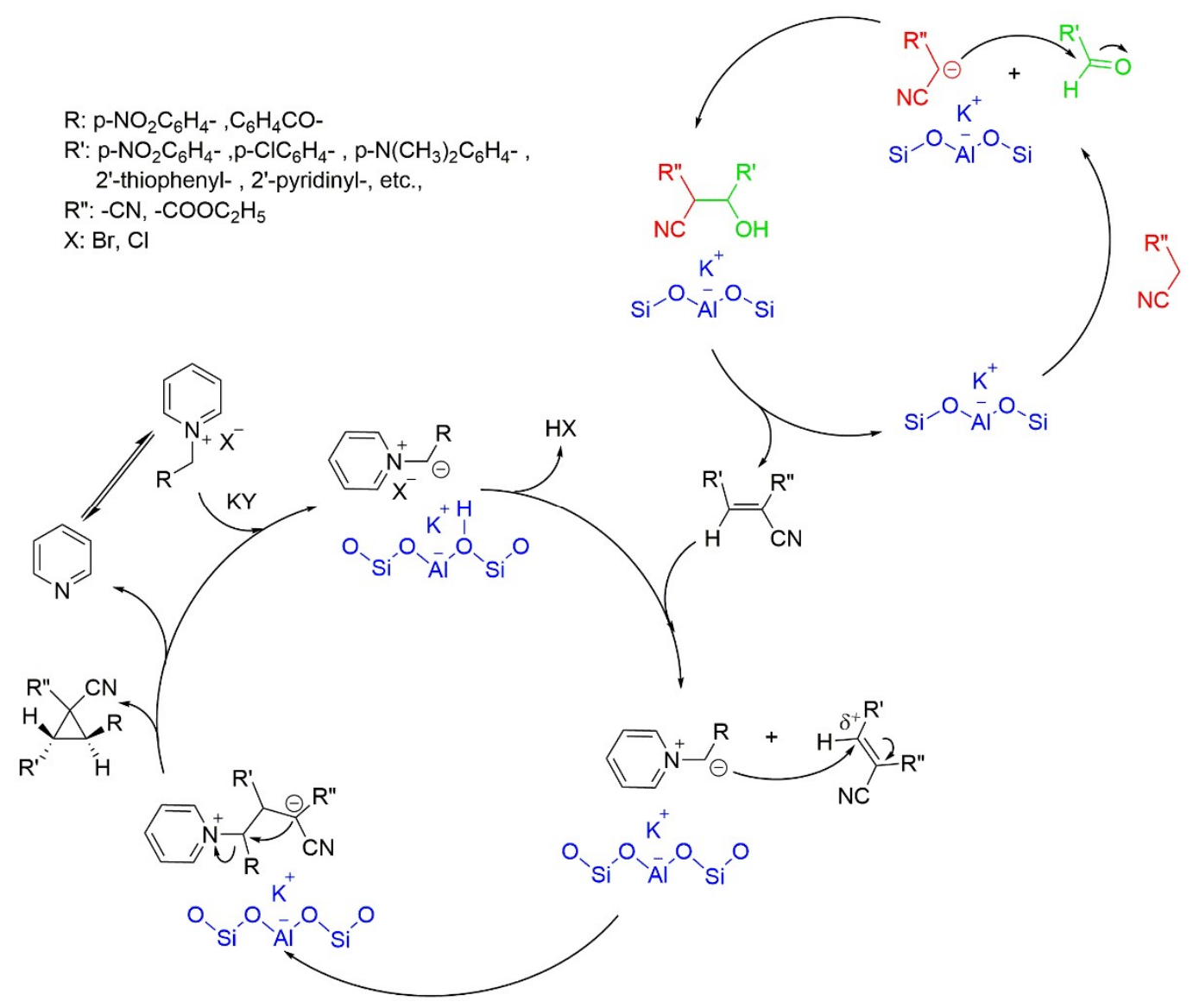

Scheme 25. Plausible mechanism for synthesis of polysubstituted cyclopropanes catalyzed by basic KY zeolites.

In conclusion, the developed protocol requires very mild conditions and is characterized by good yields, a simple work-up, and reusability of the catalyst. It was actually used for three consecutive reactions and retained its full activity.

\section{Final Remarks}

The acid-base sites of zeolites are related to the different charge of the two ions $\mathrm{Al}^{+3}$ and $\mathrm{Si}^{+4}$ present in the crystal structure, so $\left(\mathrm{AlO}_{4}\right)$ tetrahedrons have a net negative charge that requires balancing. As previously discussed, cations or protons can ensure the framework electroneutrality; in the latter case the zeolite is considered a solid acid that can give heterogeneous catalysis based on Brønsted acidity of bridging Si- $(\mathrm{OH})-\mathrm{Al}$ sites [48,49]. On the other hand, in the cationic zeolite the oxygen atoms that possess a negative charge are characterized by a certain basicity/nucleophilicity, also being the conjugate base of the corresponding acid form (Figure 1). After all, the basicity of the zeolites is a documented property, considering its deprotonating catalytic activity reported in several publications, as well as all the spectroscopic studies performed to ensure this behavior [4].

We have already discussed into the introduction the influence of the framework and extra-framework chemical composition on the number and the strength of the acidic sites of protonated zeolites and so of their catalytic activity. Since the reactions occur into the zeolite pores, it must be taken into account also of the zeolite geometry that causes the shape selectivity and the confinement 
effect of the well-defined crystal pore sizes, where the catalytic active sites are located. This molecular sieving property of the zeolites can select the desired reaction path, which gives rise to the so-called "transition state shape selectivity", that means only certain configurations of the transition state are allowed. In this regard, the modulation of the acid site strength has been considered a big challenge: it seems fairly certain that the electric field present in zeolites is crucial in stabilizing ionic pairs of the transition state [6]. On the other hand, nonuniformity of the zeolites in the proton transfer process can affect the selectivity of the chemical process, thus generating unwanted by-products. However, the attention for tuning the catalytic performance of the protonated acidic zeolites as well as the cationic basic zeolites has been reported for several chemical transformations [50,51], some of them illustrated in the present review.

Concerning the cationic zeolites, such as alkaline-LTA, it has been proven that they are naturally endowed with mild basic properties, which is a great advantage compared to the basic strength of the standardly employed organic bases. The exchange of $\mathrm{Na}^{+}$ion with larger alkali metals $\left(\mathrm{Cs}^{+}\right.$for example), which are weaker Lewis acids due to their larger size, increases to some extent the basicity of the zeolite oxides, however the increase of the steric hindrance compensates this effect, since the access to the basic sites or to the overall cavity is reduced. In any case, the basic catalytic activity is regularly modulated and these materials result in not very strong solid bases. It likely represents the main reason why cationic zeolites have been considered of less practical importance for industrial applications. In our opinion, the moderate catalytic activity as basic solid should be considered a strong point for the implementation in organic reactions of these cationic zeolites, since they are able to provide great selectivity, due to the mild condition offered, together with ease handling of the reaction mixture and a simple final work up.

In addition to these features, economic feasibility and reusability make zeolites in general attractive heterogeneous benign catalysts, which can accomplish the need to develop new environmentally friendly chemical processes and products, avoiding the use and generation of hazardous substances.

Funding: This research received no external funding.

Conflicts of Interest: The authors declare no conflict of interest.

\section{References}

1. Pines, H. Acid-Catalyzed Reactions. In The Chemistry of Catalytic Hydrocarbon Conversions, 1st ed.; Academic Press: Evanston, IL, USA, 1981; pp. 1-304. ISBN 9780323155922.

2. Weitkamp, J. Zeolites and catalysis. Solid State Ion. 2000, 131, 175-188. [CrossRef]

3. Primo, A.; Garcia, H. Zeolites as catalysts in oil refining. Chem. Soc. Rev. 2014, 43, 7548-7561. [CrossRef] [PubMed]

4. Busca, G. Acidity and basicity of zeolites: A fundamental approach. Microporous Mesoporous Mater. 2017, 254, 3-16. [CrossRef]

5. Ugal, J.R.; Hassan, K.H.; Ali, I.H. Preparation of type $4 \AA$ zeolite from Iraqi Kaolin: Characterization and properties measurements. J. Assoc. Arab Univ. Basic Appl. Sci. 2010, 9, 2-5. [CrossRef]

6. Corma, A. Inorganic Solid Acids and Their Use in Acid-Catalyzed Hydrocarbon Reactions. Chem. Rev. 1995, 95, 559-614. [CrossRef]

7. Corma, A. From Microporous to Mesoporous Molecular Sieves Materials and Their Use in catalysis. Chem. Rev. 1997, 97, 2373-2420. [CrossRef] [PubMed]

8. Busca, G. Base and Basic Materials in Chemical and Environmental Processes. Liquid Versus Solid Basicity. Chem. Rev. 2010, 110, 2217-2249. [CrossRef]

9. Haag, W.O.; Lago, R.M.; Weisz, P.B. The active site of acidic aluminosilicate catalysts. Nature 1984, 309, 589-591. [CrossRef]

10. Sartori, G.; Maggi, R. Update 1 of: Use of Solid Catalysts in Friedel-Crafts Acylation Reactions. Chem. Rev. 2011, 111, PR181-PR214. [CrossRef] 
11. Sartori, G.; Maggi, R. Protection (and Deprotection) of Functional Groups in Organic Synthesis by Heterogeneous Catalysis. Chem. Rev. 2010, 113, PR1-PR54. [CrossRef]

12. Ennaert, T.; Van Aelst, J.; Dijkmans, J.; De Clercq, R.; Schutyser, W.; Dusselier, M.; Verboekend, D.; Sels, B.F. Potential and challenges of zeolite chemistry in the catalytic conversion of biomass. Chem. Soc. Rev. 2016, 45, 584-611. [CrossRef] [PubMed]

13. Louis, B.; Gomes, E.S.; Losch, P.; Lutzweiler, G.; Coelho, T.; Faro, A., Jr.; Pinto, J.F.; Cardoso, C.S.; Silva, A.V.; Pereira, M.M. Biomass-assisted Zeolite Syntheses as a Tool for Designing New Acid Catalysts. ChemCatChem 2017, 9, 2065-2079. [CrossRef]

14. Kloetstra, K.R.; van Bekkum, H. Base and Acid Catalysis by the Alkali-containing MCM-41 Mesoporous Molecular Sieve. J. Chem. Soc. Chem. Commun. 1995, 1005-1006. [CrossRef]

15. Barthomeuf, D. Conjugate Acid-Base Pairs in Zeolites. J. Phys. Chem. 1984, 88, 42-45. [CrossRef]

16. Romero, M.D.; Rodrìguez, A.; Gòmez, J.M. Basicity in zeolite. In New Topics in Catalysis Research; McReynolds, D.K., Ed.; Nova Science Pub Inc.: Madrid, Spain, 2007; pp. 197-220. ISBN 1-60021-286-7.

17. Guo, P.; Yan, N.; Wang, L.; Zou, X. Database Mining of Zeolite Structures. Cryst. Growth Des. 2017, 17, 6821-6835. [CrossRef]

18. Titiloye, J.O.; Tschaufeser, P.; Parker, S.C. Recent Advances in Computational Studies of Zeolites. In Spectroscopic and Computational Studies of Supramolecular Systems. Topics in Inclusion Science; Davies, J.E.D., Ed.; Springer: Dordrecht, The Netherlands, 1992; Volume 4, pp. 137-185. ISBN 978-94-015-7989-6.

19. Lima, C.G.S.; Moreina, N.M.; Paixão, M.W.; Corrêa, A.G. Heterogenous green catalysis: Application of zeolites on multicomponent reactions. Nanocatalysis 2019, 15, 7-12. [CrossRef]

20. Park, S.; Biligetu, T.; Wang, Y.; Nishitoba, T.; Kondo, J.N.; Yokoi, T. Acidic and catalytic properties of ZSM-5 zeolites with different Al distributions. Catal. Today 2018, 303, 64-70. [CrossRef]

21. Arya, K.; Rajesh, U.R.; Rawat, D.S. Proline confined FAU zeolite: Heterogeneous hybrid catalyst for the synthesis of spiroheterocycles via a Mannich type reaction. Green Chem. 2012, 14, 3344-3351. [CrossRef]

22. Narasimharao, K.; Hartmann, M.; Thiel, H.H.; Ernst, S. Novel solid basic catalysts by nitridation of zeolite beta at low temperature. Microporous Mesoporous Mater. 2006, 90, 377-383. [CrossRef]

23. Saravanamurugan, S.; Riisager, A. Zeolite catalized transformation of carbohydrates to alkyl levulinates. ChemCatChem 2013, 5, 1754-1757. [CrossRef]

24. Adinolfi, M.; Barone, G.; Iadonisi, A.; Schiattarella, M. Activation of Glycoyl Trihaloacetimidates with Acid-washed Molecular Sieves in the Glycosidation Reaction. Org. Lett. 2003, 5, 987-989. [CrossRef] [PubMed]

25. Adinolfi, M.; Iadonisi, A.; Pezzella, A.; Ravidà, A. Regioselective Phenol or Carbinol Glycosidation of 17p-Estradiol and Derivatives Thereof. Synlett 2005, 12, 1848-1852. [CrossRef]

26. Adinolfi, M.; Iadonisi, A.; Ravidà, A.; Schiattarella, M. Moisture Stable Promoters for Selective $\alpha$-Fucosylation Reactions: Synthesis of Antigen Fragments. Synlett 2004, 2, 0275-0278. [CrossRef]

27. Adinolfi, M.; Iadonisi, A.; Ravidà, A.; Schiattarella, M. Versatile Use of Ytterbium(III) Triflate and Acid Washed Molecular Sieves in the Activation of Glycosyl Trifluoroacetamide Donors. Assemblage of a Biologically Relevant Tetrasaccharide Sequence of Globo H. J. Org. Chem. 2005, 70, 5316-5319. [CrossRef] [PubMed]

28. Adinolfi, M.; Barone, G.; Iadonisi, A.; Schiattarella, M. Mild benzhydrylation and tritylation of saccharidic hydroxyls promoted by acid washed molecular sieves. Tetrahedron Lett. 2003, 44, 3733-3735. [CrossRef]

29. Adinolfi, M.; Barone, G.; Iadonisi, A.; Schiattarella, M. An easy approach for the acetylation of saccharidic alcohols. Applicability for regioselective protections. Tetrahedron Lett. 2003, 44, 4661-4663. [CrossRef]

30. Kartha, R.K.P.; Mukhopadhyay, B.; Field, R.A. Practical de-O-acylation reactions promoted by molecular sieves. Carbohydr. Res. 2004, 339, 729-732. [CrossRef] [PubMed]

31. Monfregola, L.; De Luca, S. Synthetic strategy for side chain mono-N-alkylation of Fmoc-amino acids promoted by molecular sieves. Amino Acids 2011, 41, 981-990. [CrossRef]

32. Monfregola, L.; Leone, M.; Calce, E.; De Luca, S. Postsynthetic Modification of Peptide via Chemoselective N-Alkylation of Their Side Chains. Org. Lett. 2012, 14, 1664-1667. [CrossRef]

33. Calce, E.; De Luca, S. The Cysteine S-Alkylation Reaction as a Synthetic Method to Covalently Modify Peptide Sequences. Chem. Eur. J. 2016, 22, 1-11. [CrossRef]

34. Calce, E.; Leone, M.; Monfregola, L.; De Luca, S. Chemical Modifications of Peptide Sequences via S-Alkylation Reaction. Org. Lett. 2013, 15, 5354-5357. [CrossRef] [PubMed] 
35. Calce, E.; De Luca, S. Microwave heating in peptide side chain modification via cysteine alkylation. Amino Acids 2016, 48, 2267-2271. [CrossRef]

36. Calce, E.; Leone, M.; Monfregola, L.; De Luca, S. Lipidated peptides via post-synthetic thioalkylation promoted by molecular sieves. Amino Acids 2014, 46, 1899-1905. [CrossRef] [PubMed]

37. Calce, E.; Leone, M.; Mercurio, F.A.; Monfregola, L.; De Luca, S. Solid-Phase S-Alkylaion Promoted by Molecular Sieves. Org. Lett. 2015, 17, 5646-5649. [CrossRef] [PubMed]

38. Calce, E.; Digilio, G.; Menchise, V.; Saviano, M.; De Luca, S. Chemoselective Glycosylation of Peptides through S-Alkylation Reaction. Chem. Eur. J. 2018, 24, 1-9. [CrossRef] [PubMed]

39. De Luca, S.; Digilio, G.; Verdoliva, V.; Saviano, M.; Menchise, V.; Tovillas, P.; Jiménez-Osés, G.; Peregrina, J.M. A Late-Stage synthetic approach to lanthionine-containing peptides via S-alkylation on cyclic sulfamidates promoted by molecular sieves. Org. Lett. 2018, 20, 7478-7482. [CrossRef] [PubMed]

40. Azarifar, D.; Soleimanei, F.; Aliani, F. Benzylation of arylcyanamides catalyzed by acidic zeolites. J. Mol. Catal. A Chem. 2013, 377, 7-15. [CrossRef]

41. Costarrosa, L.; Ruiz-Martínez, J.; Rios, R.V.R.A.; Silvestre-Albero, J.; Rojas-Cervantes, M.L.; Sepúlveda-Escribano, A. Basic zeolites as catalysts in the N-alkylation of imidazole: Activation by microwave irradiation. Microporous Mesoporous Mater. 2009, 120, 115-121. [CrossRef]

42. Bahari, S.; Sajadi, S.M. Natrolite zeolite: A natural and reusable catalyst for one-pot synthesis of $\alpha$-aminophosphonates under solvent-free conditions. Arabian J. Chem. 2017, 10, S700-S704. [CrossRef]

43. Hasegawa, M.; Ono, F.; Kanemasa, S. Molecular sieves $4 \AA ̊$ work to mediate the catalytic metal enolization of nucleophile precursors: Application to catalyzed enantioselective Michael addition reactions. Tetrahedron Lett. 2008, 49, 5220-5223. [CrossRef]

44. Martins, L.; Hölderich, W.; Cardoso, D. Methylammonium-FAU zeolite: Investigation of the basic sites in base catalyzed reactions and its performance. J. Catal. 2008, 258, 14-24. [CrossRef]

45. Emana, A.N.; Chand, S. Alkylation of benzene with ethanol over modified HZSM-5 zeolite catalysts. Appl. Petrochem. Res. 2015, 5, 121-134. [CrossRef]

46. Sarmah, B.; Satpati, B.; Srivastava, R. Highly efficient and recyclable basic mesoporous zeolite catalyzed condensation, hydroxylation, and cycloaddition reactions. J. Colloid Interface Sci. 2017, 493, 307-316. [CrossRef] [PubMed]

47. Rama, V.; Kanagaraj, K.; Subramanian, T.; Suresh, P.; Pitchumani, K. Pyridinium ylide-assisted KY zeolite catalyzed tandem synthesis of polysubstituted cyclopropanes. Catal. Commun. 2012, 26, 39-43. [CrossRef]

48. Jiao, J.; Kanellopoulos, J.; Wang, W.; Ray, S.S.; Foerster, H.; Freude, D.; Hunger, M. Characterization of framework and extra-framework aluminum species in non-hydrated zeolites $\mathrm{Y}$ by ${ }^{27} \mathrm{Al}$ spin-echo, high-speed MAS, and MQMAS NMR spectroscopy at $\mathrm{B}_{0}=9.4$ to 17.6 T. Phys. Chem. Chem. Phys. 2005, 7, 3221-3226. [CrossRef] [PubMed]

49. Abraham, A.; Lee, S.; Shin, A.; Hong, S.B.; Prins, R.; van Bokhoven, J.A. Influence of framework silicon to aluminium ratio on aluminium coordination and distribution in zeolite Beta investigated by ${ }^{27} \mathrm{Al}$ MAS and ${ }^{27}$ Al MQ MAS NMR. Phys. Chem. Chem. Phys. 2004, 6, 3031-3036. [CrossRef]

50. Kim, H.; Cho, H.S.; Kim, C.; Choi, M. Gradual Disordering of LTA Zeolite for Continuous Tuning of the Molecular Sieving Effect. J. Phys. Chem. C 2017, 121, 6807-6812. [CrossRef]

51. Rimer, J.D. Rational design of zeolite catalysts. Nat. Catal. 2018, 1, 488-489. [CrossRef]

(C) 2019 by the authors. Licensee MDPI, Basel, Switzerland. This article is an open access article distributed under the terms and conditions of the Creative Commons Attribution (CC BY) license (http://creativecommons.org/licenses/by/4.0/). 